\title{
LA JUDICIAL REVIEW EN LA PRE-MARSHALL COURT
}

\author{
FRANCISCO FERNÁNDEZ SEGADO \\ Catedrático de Derecho Constitucional \\ Universidad Complutense de Madrid
}

SUMARIO.-

I. Algunas reflexiones sobre el diseño normativo del poder judicial:

II. La pre-Marshall Court. Su composición y sus vicisitudes.

III. La tradición del common law y el pronunciamiento a través de las seriatim opinions en los primeros años de la Corte Suprema.

IV. Los primeros casos relevantes de la Supreme Court en la etapa anterior a Marshall y la doctrina en ellos subyacente de la judicial review.

\section{ALGUNAS REFLEXIONES SOBRE EL DISEÑO NORMATIVO DEL PODER JUDICIAL}

\section{A) El Artículo III de la Constitución}

a) El Judiciary, ¿the least dangerous branch? «Publius» versus «Brutus»

I. El Art. III de la Constitución de 1787 comienza señalando: «The judicial power of the United States, shall be vested in one Supreme Court, and in such inferior Courts as the Congress may from time to time ordain and establish». Ubicado en una estructura presidida por el principio de separación de poderes, que ordena e impregna el American constitutional law ${ }^{1}$, el poder judicial se nos presenta, en palabras de Hamilton que han devenido míticas, como «the least dangerous (branch/department)»², en cuanto que, debido

1 En palabras de TRIBE, «just at the Colossus once strode the wine-dark waters of the harbour of Rhodes, so the separation of powers commands and pervades American constitutional law». L. TRIBE: American Constitutional Law, volume one, third edition, Foundation Press, New York, 2000, pág. 124.

2 «Whoever —escribe Hamilton en el artículo n 78 de los Federalist Papers — attentively considers the different departments of power must perceive, that in a government in which they are separated from each other, the judiciary, from the nature of its functions, will always be the least dangerous to the political rights of the 
a la naturaleza de sus funciones, la situación de este poder no le permitirá perjudicar los derechos políticos constitucionalmente contemplados, o por lo menos, le será más difícil hacerlo de lo que lo puedan hacer los otros dos poderes, el legislativo y el ejecutivo. Bien es verdad que esta célebre caracterización de Hamilton puede ser comprendida desde una perspectiva estratégica, o lo que es igual, como una respuesta puntual a la notablemente crítica descripción del poder judicial que en sus ensayos anti-federalistas iba a hacer «Brutus» ${ }^{3}$, quien explicitaría a través de los mismos muchas de las objeciones a la Constitución expuestas por otros escritos antifederalistas. Para Diamond, no cabe la más mínima duda de que los artículos 78 a 82 de los Federalist Papers 4 aparecen como un intento heroico («an heroic attempt») para cambiar la fuerza de las predicciones de «Brutus» en su provecho, esto es, en provecho de la Constitución, no contra ella ${ }^{5}$.

En el undécimo de sus artículos, «Brutus» introducía la discusión sobre el poder judicial diseñado por la Constitución, recomendando una mirada precisa a esta «rama» del gobierno federal que, a juicio del ensayista, estaba colocada en una situación completamente inaudita en un país libre («in a situation altogether unprecedent in a free country»), juicio que parecía responder a la apreciación de que el Judiciary se hallaba facultado para interpretar la Constitución de acuerdo con su espíritu («according to its spirit»), no quedando limitado a sus palabras, lo que le llevaría a la conclusión final de que el Judiciary tenía un derecho «independent of the legislature, to give a construction to the constitution and every part of it, and there is no power provided in this system to correct their construction or do it away» ${ }^{6}$. En su ensayo ${ }^{\circ} \mathrm{XV}$, «Brutus» explicita su conclusión final sobre el «departamento judicial», que no es sino la de que se diseña un poder que queda más allá del alcance de cualquier otro poder en el gobierno o en la comunidad. «In short (concluye en alusión a los jueces) they are independent of the people, of the legislature, and of every power under heaven ${ }^{7}$. A la vista de tales

constitution». Apud The Founders' Constitution, edited by P. B. KURLAND-R. LERNER, volume four, The University of Chicago Press, Chicago and London, 1987, pág. 142.

3 Entre el 18 de octubre de 1787 y el 10 de abril de 1788, bajo el seudónimo de «Brutus», se publicaban en el New York Journal un total de 18 ensayos, como parte del debate sobre la ratificación de la Constitución federal por ese Estado. Aún hoy, no se conoce con total certeza la identidad de «Brutus», aunque se sospecha que los ensayos fueron escritos por Robert Yates. El seudónimo puede explicarse por la supuesta finalidad de los mismos de prevenir que la nueva Constitución posibilitase el cambio de una república libre a un régimen despótico quizá encabezado por un César. Si se recuerda que Alexander Hamilton fue un enorme conocedor del pensamiento del mundo clásico, griego y romano, y un gran admirador de Julio César, el término «Brutus» vendría implícitamente a marcar el rechazo radical del pensamiento de uno de los más sólidos intelectuales de la Convención Constituyente de Filadelfia, declarado defensor del Judiciary. Muy significativamente, los ensayos números XI al XVI, dedicados principalmente a la discusión sobre el poder judicial nacional o federal, fueron publicados entre el 31 de enero y el 10 de abril de 1788, fechas que una buena conocedora de esta etapa como es Diamond, considera lo suficientemente significativas como para entender que los artículos de «Publius», seudónimo utilizado por Hamilton, sobre el Judiciary en «El Federalista», son claramente una respuesta a «Brutus». Cfr. al efecto, A. S. DIAMOND: "The Anti-Federalist "Brutus"», en Political Science Reviewer, No. 6, Fall 1976, págs. 249 y ss.; en concreto, pág. 269.

4 Los 85 ensayos integrantes de los Federalist Papers pueden verse en HAMILTON, MADISON y JAY: El Federalista, Fondo de Cultura Económica, $1^{a}$ reimpr. de la $2^{a}$ ed. española, México, 1974. El artículo $\mathrm{n}^{\circ} 78$ en págs. 330 y ss.

5 A. S. DIAMOND: «The Anti-Federalist "Brutus"», op. cit., pág. 277.

6 Ibidem, pág. 270.

7 Ibidem, pág. 275. 
apreciaciones, nos podemos interrogar acerca de cuál era, en realidad, la fuente última de preocupación de «Brutus» frente al diseño constitucional del poder judicial. Habría que contestar que no muy distinta de la latente en otros escritos antifederalistas. La alarma de «Brutus» no proviene tanto de que el poder judicial esté en algún sentido por encima del legislativo federal, sino más bien de que el judiciary produzca una total subversión de los judiciaries estatales y, más ampliamente, del supuestamente poder soberano de los Estados. El párrafo que subsigue, extraído del undécimo ensayo de «Brutus», es tan elocuente que no merece apostilla alguna: «I mean, an entire subversion of the legislative, executive and judicial powers of the individual states. Every adjudication of the supreme court, on any question that may arise upon the nature and extent of the general government, will affect the limits of the state jurisdiction» ${ }^{8}$.

Es más que probable que en el trasfondo de la referida preocupación de «Brutus» se halle la función judicial de la judicial review, que, no obstante no haber sido recogida en el Art. III de la Constitución, en modo alguno había sido ajena al debate en la Convención Constitucional. Digamos, ante todo, que difícilmente podía haberlo sido, pues la defensa de la «judicial authority over unconstitutional legislation» se desarrolló en un momento coincidente con el período de redacción del texto constitucional ${ }^{9}$, y ello, añadiremos, al margen ya de la tradición colonial proclive al reconocimiento de tal potestad judicial, en la que ahora no podemos entrar.

II. La idea de la supremacía de un bloque normativo, que había de quedar en una posición de superioridad sobre el Derecho emanado de los Estados, y a la que se habían de anudar ciertas consecuencias jurídicas, estuvo muy presente desde el primer momento en el Continental Congress. Una prueba fehaciente de ello la encontramos en que el 21 de marzo de 1787, el Congreso creado al amparo de los Articles of the Confederation aprobaba por unanimidad una resolución que anticipaba la celebérrima supremacy clause del Art. VI de la Constitución. A través de la misma, acordaba «that the legislatures of the several states cannot of right pass any act or acts, for interpreting, explaining, or construing a national treaty or any part of clause of it; nor for restraining, limiting or in any manner impeding, retarding, or counteracting the operation and execution of the same, for that on being constitutionally made, ratified and published, they become in virtue of the confederation, part of the law of the land, and are not only independent of the will and power of such legislatures, but also binding and obligatory upon them» ${ }^{10}$. Bien es verdad que, como acaba de verse, la cláusula aprobada en marzo tenía como referente a los tratados, pero la referencia a ese «law of the land» ya anticipaba que otras normas, primariamente la Constitución, habrían de incorporarse a ese bloque normativo. Este planteamiento dejaba subyacente la cuestión del órgano u órganos que habrían de reaccionar jurídicamente cuando las normas dotadas de esa primacía fueran vulneradas por normas inferiores.

8 Ibidem, pág. 277.

9 S. SNOWISS: Judicial Review and the Law of the Constitution, Yale University Press, New Haven and London, 1990, pág. 38.

10 Apud R. L. CLINTON: Marbury v. Madison and Judicial Review, University Press of Kansas, Lawrence (Kansas), 1989, pág. 61. 
Hubiera resultado perfectamente coherente con el anterior planteamiento que la Convención Constitucional abordara la cuestión, lo que era tanto como decir que tratara el tema de la judicial review, pero lo cierto, vaya esta precisión por delante, es que en la misma no hubo una discusión general sobre la judicial review. Ello no obstante, no faltaron diferentes apreciaciones o comentarios en torno a tan trascendente cuestión, habiéndose constatado ${ }^{11}$ que la judicial review llegó a ser un tópico para la discusión en la Convención sólo después de que una propuesta para adoptar un Council of revision hubiese sido considerada. El mencionado Consejo habría estado integrado por el Presidente y por miembros del Judiciary, ejerciendo un poder de veto frente a las leyes cuando ello se entendiere apropiado, y hay que presuponer que se consideraría como tal cuando la ley se opusiese a la Constitución. El Council of revision fue rechazado, dando paso, por cierto, a la potestad de veto presidencial, principalmente porque los delegados a la Convención lo percibieron como una violación del principio constitucional de la separación de poderes, pero también porque varios delegados esgrimieron que la específica inclusión del Judiciary en ese Council era innecesaria, en cuanto que, como jueces, dispondrían de la facultad de llevar a cabo un control sobre la legislación ( «a check on legislation») a fin de pronunciarse sobre su constitucionalidad. Recuerda Corwin ${ }^{12}$ a este respecto, que cuando el 4 de junio se debatió esta proposición del Council of revision, varios relevantes delegados, como Gerry de Massachusetts, Wilson de Pennsylvania, Mason de Virginia y Luther Martin de Maryland, sostuvieron en diferentes momentos la facultad de la Corte Suprema de pronunciarse, al hilo de un litigio del que conociera, sobre la constitucionalidad de la legislación del Congreso. En cualquier caso, la discusión constituyente sobre la judicial review fue reducida, muy puntual. Tampoco debe extrañar que así fuera por cuanto el ejercicio de esta función por los tribunales podía considerarse en cierto modo habitual mucho antes de la Convención de Filadelfia. Por poner un ejemplo, en la mencionada sesión del 4 de junio, Gerry, —que como Gobernador de Massachusetts daría su nombre a la viciosa práctica de manipulación de las circunscripciones electorales: Gerrymandering — en refencia al principio de invalidación judicial de las leyes con base en su inconstitucionalidad, formulaba la siguiente observación: «In some of the states the judges had actually set aside laws as being against the constitution. This was done too with general approbation ${ }^{13}$.

El propio Madison, cuyo relevante rol en la Convención de Filadelfia es bien conocido, en un determinado momento del debate constituyente, afirmó con toda franqueza que «a law violating a constitution established by the people themselves would be considered by the Judges as null and void» ${ }^{14}$. Ciertamente, la posición de Madison

11 P. A. DIONISOPOULOS-P. PETERSON: «Rediscovering the American Origins of Judicial Review: A Rebuttal to the Views Stated by Currie and Others Scholars», en John Marshall Law Review (J. Marshall L. Rev.), Vol. 18, 1984-1985, págs. 49 y ss.; en concreto, págs.56-57.

12 E. S. CORWIN: «The Supreme Court and Unconstitutional Acts of Congress», en Michigan Law Review (Mich. L. Rev.), Volume IV, 1905-1906, págs.616 y ss.; en concreto, pág. 619.

13 A. SCOTT: «Holmes vs. Walton: The New Jersey Precedent», en The American Historical Review, Vol. 4, No. 3, April 1899, págs.456 y ss.; en concreto, pág. 464.

14 R. L. KETCHAM: «James Madison and Judicial Review», en Syracuse Law Review (Syracuse L. Rev.), Volume 8, 1956-1957, págs. 158 y ss.; en concreto, pág. 159. 
acerca de la judicial review cambiará años después ${ }^{15}$, pero en el momento constituyente su postura parecía nítida, y justamente en ella sustentaría su rechazo, por innecesaria, de una específica cláusula constitucional prohibiendo las retrospective laws que dañaran una obligación contractual, por cuanto «the prohibition on ex post facto» obligaba a los jueces, siempre según Madison, a declarar las interferencias legales sobre las obligaciones contractuales nulas y sin valor alguno («null and void»). En fin, Charles E. Hughes, quien fuera Chief Justice (entre 1930 y 1941), en su clásica obra sobre la Corte Suprema, se hace eco de cómo un autor tan relevante como Beard, en un cuidadoso análisis de las opiniones de los miembros de la Convención Federal, ha demostrado, que de los veinticinco miembros que, por razones de su personalidad, capacidad y asiduidad, fueron el elemento dominante de la Convención, diecisiete se pronunciaron directa o indirectamente por la judicial review ${ }^{16}$.

Desde otro punto de vista, justamente el de la propia normación constitucional, puede sostenerse que cuando los Framers emprendieron la tarea de establecer una serie de limitaciones formales sobre el poder legislativo, dejaron poco lugar para las dudas («they left little room for doubt») en cuanto a lo que habían hecho, actuación que un sector de la doctrina ${ }^{17}$ ha compendiado en esta tríada de previsiones: a) en primer término, los constituyentes dispusieron una revisión política del ejecutivo a través de la institucionalización del veto power; b) en segundo lugar, los Framers establecieron una facultad de revisión del legislativo a través de su capacidad de pasar por encima («the override capacity») del veto ejecutivo, y c) por último, los autores de la Constitución previeron una revisión judicial limitada («limited judicial review») en casos de naturaleza judicial.

A todo ello era inexcusable añadir un hecho palmario, del que dejaba constancia Gerry en su intervención en la Convención: diferentes tribunales estatales, en New Jersey, Virginia, New York, Massachusetts y North Carolina, entre varios otros Estados, habían controlado leyes de sus Legislaturas. En este contexto, no debe extrañar que Charles Warren, el gran historiador de la Supreme Court, tras rastrear la primera historia del judiciary, observara que aunque las actitudes de los estadistas del Sur y de los antifederalistas pudieran cambiar ulteriormente, en los inicios fue claro su apoyo a la judicial review ${ }^{18}$. Más aún, el mismo Jefferson, en posición antitética a la que adoptaría frente a la Marshall Court, en una carta dirigida a Madison en marzo de 1789, parecía apoyar la atribución a los jueces de la facultad de la judicial review ${ }^{19}$, algo que podría venir corroborado por otra carta de Jef-

15 En octubre de 1788, en una carta dirigida a John Brown, de Kentucky, ya parece estar modulando su posición al respecto. Estas son algunas de las reflexiones vertidas por su pluma: «In the state constitutions, and indeed in the federal one also, no provision is made for the case of a disagreement in expounding them; and as the courts are generally the last in making the decision it results to them, by refusing or not refusing to execute a law, to stamp it with its final character. This makes the judicial department paramount in fact to the legislature, which was never intended and can never be proper». Apud E. S. CORWIN: "The Supreme Court and Unconstitutional Acts of Congress», op. cit., pág. 621.

16 C. E. HUGHES: La Suprema Corte de los Estados Unidos, $2^{a}$ ed. en español, Fondo de Cultura Económica, México, 1971, pág. 95.

17 R. L. CLINTON: Marbury v. Madison and Judicial Review, op. cit., pág. 25.

18 De ello se hacen eco P. Allan DIONISOPOULOS y Paul PETERSON: «Rediscovering the American Origins of Judicial Review...», op. cit., pág. 61.

19 En una carta escrita a Madison en marzo de 1789, en relación a la discusión abierta en torno a la incorporación a la Constitución de un Bill of Rights, Jefferson efectuaba las siguientes reflexiones: «In the arguments in favor of a declaration of rights, you omit one which has great weight with me, the legal check which 
ferson al propio Madison, escrita esta vez desde París en noviembre de 1788, en la que alababa los escritos recogidos en los Federalist Papers, — en los que, no lo olvidemos, Hamilton hacía una decidida defensa de la facultad judicial de la judicial review- calificándolos como «the best commentary on the principles of government which ever was written ${ }^{20}$. En cualquier caso, no puede ignorarse que una cosa era admitir en abstracto la facultad de la revisión judicial de la constitucionalidad de las leyes, y otra bien diferente la de si los tribunales federales en general y la Corte Suprema en particular podían fiscalizar leyes estatales. Y entre estos posicionamientos proclives a la judicial review de relevantes antifederalistas, el que aún resulta mucho más sorprendente, casi increíble, es el de Spencer Roane, quizá el enemigo por excelencia de John Marshall, presidente del Supremo Tribunal del Estado de Virginia, amigo íntimo de Jefferson y frustrado aspirante a la Supreme Court's Chief Justiceship, además de feroz hipercrítico con la labor de Marshall como presidente de la Corte, incluyendo el posicionamiento de ésta en torno a la judicial review. En un caso desarrollado ante su tribunal en 1793, Roane defendía con ardor no ya la facultad, sino el deber de ejercer la función de la judicial review ${ }^{21}$, con lo que su posterior crítica a Marshall se revela como un enorme ejercicio de cinismo.

En resumen, de modo implícito, pero asimismo con el complemento de explícitas, aunque puntuales, intervenciones de delegados, la judicial review estuvo presente en la Convención Constitucional. Hamilton, en el celebérrimo artículo LXXVIII de «El Federalista» no haría sino extraer las consecuencias últimas de todo ello. De ahí que en absoluto podamos estar de acuerdo con la tesis de Snowiss, para la que los debates de la Convención indican que la ley fundamental se sobreentendía que vinculaba moral y políticamente, no jurídicamente («fundamental law was understood to bind morally and politically, not legally» $)^{22}$.

III. Al margen ya de los ensayos publicados por «Brutus», no debe extrañar en exceso la posición de Hamilton en los Federalist Papers — que, por lo demás, son una clásica glo-

it puts into the hands of the judiciary. This is a body, which if rendered independent, and keep strictly to their own department merits great confidence for their learning and integrity». Apud P. A. DIONISOPOULOS-P. PETERSON: «Rediscovering the American Origins...», op. cit., págs. 59-60.

20 Alexander Hamilton and the Founding of the Nation, edited by R. B. MORRIS, Harper Torchbooks, Harper \& Row, Publishers, New York/Evanston/London, 1969 (first published in 1957 by The Dial Press, New York), pág. 160 .

21 Estas son algunas de las reflexiones del Justice Spencer Roane: «It is the province of the Judiciary to expound the laws (...). The Judiciary may clearly say that a subsequent statute had not changed a former for want of sufficient words, though it was perhaps intended it should do so; it may say, too, that an Act of Assembly has not changed the Constitution, though its words are expressly to that effect, because a Legislature must have both the power and the will (...) to change the law (...)».

«In expounding laws — continua razonando Spencer Roane — the Judiciary considers every law which relates to the subject. Would you have them shut their eyes against that law which is of the highest authority of any, or against a part of that law which either by its words or by its spirit denies to any but the people the power to change it? In fact, it may almost be said that this function of the Court is a judicial duty rather than a power - a duty to apply the law, in litigated cases which come before the Court for decision. In such a case, if one party relies on an Act of Congress and the other party contends that the Act of Congress violates the Constitution, the Court has to decide which law governs». Apud C. WARREN: Congress, the Constitution and the Supreme Court, Johnson Reprint Corporation, New York and London, 1968 (the edition was originally published in 1925 by Little, Brown, and Company), pág. 58.

22 S. SNOWISS: Judicial Review and the Law of the Constitution, op. cit., pág. 42. 
sa antes que una guía autorizada sobre el texto original, lo que explicaría ciertas diferencias en su comprensión entre los tres autores ${ }^{23}$ — por entero proclive a la consideración de la Constitución como ley suprema, y a la encomienda al poder judicial de su defensa a través de la facultad de revisión judicial, por cuanto tanto la inicial ausencia en el texto constitucional de un Bill of Rights, como la redacción del Art. III ${ }^{24}$, constituyeron los aspectos más controvertidos en el proceso de ratificación constitucional por los Estados ${ }^{25}$. De ahí que Hamilton, sin duda alguna, la más brillante figura política de su edad, dotado de una mente aguda, ágil y perceptiva, que durante toda su vida deslumbró a quienes le rodeaban, con pruebas de agudeza realmente prodigiosas ( «with truly prodigious feats of acuity» ${ }^{26}$, se esforzara en volcar toda su autoridad intelectual, en lo que ahora interesa, en sustentar las virtudes del poder judicial someramente esbozado por el Art. III.

En cualquier caso, si se atienden las reflexiones formuladas por Hamilton en los $\mathrm{Fe}$ deralist Papers acerca del judiciary y de su facultad de revisión judicial de las leyes, lo primero que sorprende es la postura un tanto críptica que subyace en el artículo XXXIII del Federalista, cuando, tras plantear la cuestión de quién había de juzgar sobre la necesidad y conveniencia de las leyes que se expidieran con el objeto de llevar a efecto los poderes de la Unión, respondía «que el gobierno nacional, como cualquier otro, debe juzgar en primera instancia sobre el ejercicio adecuado de sus poderes, y sus electores en último término», para apostillar de inmediato: «Si el gobierno federal sobrepasara los justos límites de su autoridad (...), el pueblo, de quien es criatura, debe invocar la norma que ha establecido y tomar las medidas necesarias para reparar el agravio hecho a la Constitución», tras lo que añadía: «La constitucionalidad de una ley tendrá que determinarse en todos los casos según la naturaleza de los poderes en que se funde», afirmaciones poco claras y, desde luego, bastante contradictorias con las que finalmente plasmaría en el artículo LXXVIII. Bien pudiera pensarse, a la vista del artículo XXXIII, que Hamilton circunscribe la judicial review a las leyes estatales. Crosskey, que se ha referido con cierto detalle a este punto ${ }^{27}$, iba, sin embargo, a considerar las reflexiones vertidas en el artículo XXXIII en perfecta armonía con las efectuadas por Hamilton en la Convención Constituyente de Filadelfia. «They are — escribe el mencionado autor — in

23 W. H. HAMILTON: «The Constitution-Apropos of Crosskey», en The University of Chicago Law Review (U. Chi. L. Rev.), Volume 21, 1953-1954, págs.79 y ss.; en concreto, pág. 80.

24 Por poner un ejemplo, en el periódico de Boston Independent Chronicle, en su edición del 5 de marzo de 1789, no obstante hallarse ya ratificada la Constitución, pero con vistas a la elaboración de la Judiciary Act y, en su caso, a la aprobación de las Enmiendas conteniendo la declaración de derechos, se identificaban como partes necesitadas de mejoras esenciales («essential improvements»), «a bill of rights, and new and additional checks in the Judiciary department». Apud M. MARCUS-N. WEXLER: «The Judiciary Act of 1789: Political Compromise or Constitutional Interpretation?», en Origins of the Federal Judiciary. Essays on the Judiciary Act of 1789, edited by M. MARCUS, Oxford University Press, New York/Oxford, 1992, págs. 13 y ss.; en concreto, pág. 27.

25 El proceso culminaba el 21 de junio de 1788, cuando la Convención de New Hampshire, por 57 votos frente a 46, decidía aprobar la Constitución nacional, cumpliéndose así el requisito constitucionalmente exigido de que, al menos las Convenciones de nueve Estados, ratificasen el texto.

26 D. STALOFF: Hamilton, Adams, Jefferson. The Politics of Enlightenment and the American Founding, Hill and Wang, New York, 2005, pág. 46.

27 W.W. CROSSKEY: Politics and the Constitution in the History of the United States, The University of Chicago Press, volume II, 2nd impression, Chicago, 1955, págs. 1026-1028. 
accord with his known conviction as to what was desirable in the Government of the United States». Tales convicciones quedarían explicitadas en las sugerencias hechas por Hamilton en la Convención Federal, en las que defendería «a legislature with "power to pass all laws whatsoever", a power which would have left no room at all for judicial review ${ }^{28}$. Es por todo ello por lo que, siempre según Crooskey, cuyas tesis no han dejado de suscitar notable polémica, dicho sea al margen, la posición sustentada por Hamilton en el $\mathrm{n}^{\circ}$ LXXVIII de los Federalist Papers, proclive al reconocimiento de un derecho de revisión judicial de la Corte Suprema frente a los actos legislativos del Congreso, no sería sino el resultado de los ataques contra la Supreme Court llevados a cabo «by some of the abler "State'Rights" writters», que la tildarían de una «nacionalizing or consolidating agency». En definitiva, los comentarios vertidos por Hamilton en el $n^{\circ}$ LXXVIII no pueden desligarse de los ataques que los escritores antifederalistas — «Brutus», pero no sólo él — iban a vertir durante la campaña de ratificación de la Constitución Federal por las Convenciones estatales, en contra del diseño constitucional del poder judicial, ante la sospecha de que el judiciary estaba concebido como un poder centralizador frente a los Estados integrantes de la Unión, intuyéndose que la judicial review era el instrumento pensado para controlar tan sólo las leyes de las Legislaturas estatales. Así las cosas, el cambio de rumbo de Hamilton en el artículo LXXVIII del Federalista era obligado desde todos los puntos de vista.

En el celebérrimo artículo LXXVIII, Hamilton hace una sólida defensa de la supremacía de la Constitución y del derecho de los tribunales a declarar nulos («null and void») los actos legislativos aprobados con violación de la Constitución y de los tratados. Tras considerar que «la independencia completa de los tribunales de justicia es particularmente esencial en una Constitución limitada», entendiendo por tal «la que contiene ciertas prohibiciones expresas aplicables a la autoridad legislativa», Hamilton se ocupará del «derecho de los tribunales a declarar nulos los actos de la legislatura, con fundamento en que son contrarios a la Constitución», admitiendo que tal facultad «ha suscitado ciertas dudas como resultado de la idea errónea de que la doctrina que la sostiene implicaría la superioridad del poder judicial frente al legislativo», objeción frente a la que replicará que «no hay proposición que se apoye sobre principios más claros que la que afirma que todo acto de una autoridad delegada, contrario a los términos del mandato con arreglo al cual se ejerce, es nulo. Por lo tanto, ningún acto legislativo contrario a la Constitución puede ser válido. Negar esto equivaldría a afirmar que el mandatario es superior al mandante, que el servidor es más que su amo, que los representantes del pueblo son superiores al pueblo mismo y que los hombres que obran en virtud de determinados poderes pueden hacer no sólo lo que éstos no permiten, sino incluso lo que prohíben».

Los argumentos de Hamilton en favor de la supremacía de la Constitución y del derecho de los tribunales a declarar nulos los actos legislativos dictados en violación de la Constitución, como antes dijimos, pueden visualizarse desde la óptica de una contrarréplica a los poco antes expuestos por «Brutus» y demás escritores antifederalistas, pero visualizarlos única y exclusivamente desde esa vertiente tan coyuntural no creemos que fuera del todo exacto, pues no puede olvidarse que la voz potente y docta de Hamilton en favor de la judicial review ya había sido levantada en un momento tan temprano como en

28 Ibidem, pág. 1027.

UNED. Teoría y Realidad Constitucional, núm. 28, 2011, pp. 133-178. 
1784, cuando él intervino como abogado de la defensa en el caso de Rutgers $v$. Waddington, del que nos ocuparemos más adelante, sin olvidar que en un speech pronunciado en marzo de 1787 en la New York Assembly, demostrando su conocimiento del mundo clásico, recurría al precedente de Cicerón en apoyo de su posición favorable a la judicial review $^{29}$.

b) El carácter vitalicio de los jueces federales

El Art. III dejó abiertas, entre otras varias trascendentales cuestiones, las atinentes al número y tipo de los tribunales federales inferiores, y al número de integrantes de la Corte Suprema. Sin embargo, precisó un aspecto de la mayor relevancia en relación al estatuto jurídico de los jueces federales: el carácter vitalicio en el ejercicio de sus cargos, o como se ha dicho, «an appointed judiciary serving at a guaranteed salary for life, subject only to impeachment» ${ }^{30}$.

La Carta federal iba a diferir en este punto muy considerablemente del tratamiento dado al mismo por las Constituciones estatales aprobadas entre 1776 y 1787. Ninguna Carta estatal había ido tan lejos. Se trataba de una solución extrema, que quizá sólo podía explicarse por la fuerza de los compromisos establecidos en la Convención de Filadelfia en pro de un poder judicial independiente («an independent judiciary»). Más aún, se ha considerado que la versión que del principio de separación de poderes dieron los Framers se concibió como dispuesta en favor de un judiciary independiente de la vox populi ${ }^{31}$, lo que, sin embargo, creemos que exige una matización: el judiciary en general y la Corte Suprema muy en especial, estaban llamados a salvaguardar la primigenia expresión de la voluntad constituyente del pueblo, controlando el acomodo a la misma de quienes en cada momento histórico iban a expresar la voluntad popular.

Ante la disposición constitucional de la sección $1^{\text {a }}$ del Art. III, que declaraba el carácter vitalicio de los jueces federales mientras observaran buena conducta ( «The Judges, both of the supreme and inferior Courts, shall hold their Offices during good Behaviour»), disposición que no dejaría de ser controvertida, Hamilton recurriría para fundamentarla a la trascendental función de los tribunales como garantes de la Constitución, conectándola a la par con la salvaguarda del principio de independencia judicial: «Si los tribunales de justicia — puede leerse en el artículo LXXVIII de «El Federalista»— han de ser considerados como los baluartes de una Constitución limitada, en contra de las usurpaciones legislativas, esta consideración suministrará un argumento sólido en pro de la tenencia permanente de las funciones judiciales, ya que nada contribuirá tanto como esto a estimular en los jueces ese espíritu independiente que es esencial para el fiel cumplimiento de tan arduo deber». En definitiva, el carácter vitalicio de los jue-

29 «Cicero — afirmaba Hamilton ante la Asamblea newyorkina - the great Roman orator and lawyer, lays it down as a rule that when to laws clash, that which relates to the most important matters ought to be preferred. If this rule prevails, who can doubt what would be the conduct of the judges (...)?». Apud Alexander Hamilton and the Founding of the Nation, edited by Richard B. MORRIS, op. cit., pág. 218.

30 G. CASPER; «The Judiciary Act of 1789 and Judicial Independence», en Origins of the Federal Judiciary. Essays on the Judiciary Act of 1789, edited by Maeva Marcus, Oxford University Press, New York/Oxford, 1992, págs. 281 y ss.; en concreto, pág. 285.

31 Ibidem, pág. 290. 
ces se vinculó inextricablemente con el principio de independencia, siempre omnipresente en la vida norteamericana.

Quizá sea útil recordar a este respecto que ya en la Declaration of Independence ( 4 de julio de 1776), entre los veinticinco agravios expuestos por los colonos frente al Monarca británico, figuraba uno atinente a la falta de independencia de los jueces. «He (puede leerse en ese agravio en obvia referencia al Rey) has made Judges dependent on his Will alone, for the tenure of their offices, and the amount and payment of their salaries». Quiere ello decir, que ya desde el primer momento de su vida independiente los norteamericanos elevaron el principio de independencia judicial a la categoría de verdadera clave de bóveda del futuro edificio gubernamental. Y este principio vino siendo sistemáticamente reiterado tanto por las Declaraciones de Derechos como por las Constituciones de los Estados. Buen ejemplo de ello lo encontramos en la Sección 22 de la Delaware Declaration of Rights and Fundamental Rules, de 11 de septiembre de 1776, en la que puede leerse: «That the Independency and Uprightness of Judges are essential to the impartial Administration of Justice, and a great Security to the Rights and Liberties of the People». Ahora bien, como antes se dijo, al principio de independencia judicial no se anudó en los Estados, como regla general ${ }^{32}$, el carácter vitalicio en el ejercicio de su cargo por los jueces.

En fin, aunque no diremos que a modo de contrapartida, sí que debe tenerse presente que la Constitución, como antes se señaló, dejaba la composición de la Supreme Court, incluyendo el número de sus miembros, a la decisión del Congreso, que ciertamente no podía remover a los Justices, salvo a través del mecanismo excepcional del impeachment, pero sí podía alterar su número. Y el Congreso disponía asimismo de la facultad de crear nuevos tribunales federales o de reestructurar los existentes en cualquier momento en que así lo considerara oportuno.

c) El Judiciary como titular del «judicial power».

I. Otra previsión constitucional de particularísima relevancia fue la de otorgar al judiciary «the judicial power», o lo que es igual, un poder exclusivamente judicial, no político, lo que no es óbice para que se admita que la Corte Suprema también desarrolla ciertas funciones de policy-making ${ }^{33}$. El mencionado «poder judicial» queda nítidamente reflejado en la cláusula primera de la Sección $2^{a}$ del Art. III, que se refiere reiteradamente al conocimiento por el judiciary de «cases and controversies». Los Framers rechazaron

32 La Constitución de Kentucky, ciertamente posterior a la Constitución federal (es de 1799), siguió en parte la regla de la Constitución de 1787, disponiendo en la Sección tercera de su Art. $4^{\circ}$ que «the judges, both of the supreme and inferior courts, shall hold their offices during good behavior», aunque la propia disposición añadía de inmediato: "but for any reasonable cause, which shall not be sufficient ground of impeachment, the governor shall remove any of them on the address of two-thirds of each house of the general assembly».

33 Autor tan cualificado como McCloskey considera que algo fascinante acerca de la Supreme Court ha sido el hecho de que combina funciones judiciales ortodoxas con funciones de policy-making en una compleja mixtura. Y el poder de la Corte es justificado por el hecho de que la mixtura es mantenida en un delicado equilibrio, pero el hecho de que debe ser mantenido en tal equilibrio explica la limitación de ese poder. R. G. McCLOSKEY: The American Supreme Court, 2nd edition (revised by Sanford Levinson), The University of Chicago Press, Chicago \& London, 1994, pág. 12. 
otorgar a la Corte Suprema un poder de veto o de revisión de la legislación, circunscribiendo la actuación del judiciary en general y de la Supreme Court en particular a la existencia de un caso litigioso planteado ante el órgano judicial. A tenor del inciso inicial de la cláusula primera de la Sección $2^{a}$ del Art. III de la Constitución: «The judicial Power shall extend to all Cases, in Law and Equity, arising under this Constitution, the Laws of the United States, and Treaties made, or which shall be made, under their Authority...». Como decía Hamilton en el artículo LXXX de The Federalist Papers, no puede admitir controversia el que la autoridad judicial de la Unión deba extenderse a todos los casos que surjan con motivo de las leyes de los Estados Unidos, promulgadas por éstos en ejercicio de sus facultades justas y constitucionales de legislación, pues ello descansa en la consideración obvia de que debe existir siempre un medio constitucional de impartir eficacia a las disposiciones constitucionales, pues —se interroga Hamilton- ¿de qué servirían, por ejemplo, las restricciones a las facultades de las legislaturas locales, si no existe algún procedimiento constitucional para exigir su observancia? En el mismo artículo LXXX, trataría de delimitar más adelante lo que había de entenderse por «controversias que surjan con motivo de la Constitución», por oposición a las que «surjan con motivo de las leyes de los Estados Unidos». Hamilton conecta la diferencia entre uno y otro tipo de controversias a las restricciones impuestas a las facultades de las legislaturas locales, poniendo un ejemplo, el de que las legislaturas estatales no deben emitir papel moneda, prohibición que deriva de la Constitución y que nada tiene que ver con las leyes de los Estados Unidos. Consecuentemente, si a pesar de esa interdicción, una legislatura emitiese papel moneda, las controversias a que ello daría lugar serían casos que surgirían de la Constitución y no de las leyes de los Estados Unidos. No han faltado interpretaciones, como la de Corwin hace más de un siglo ${ }^{34}$, que verían en esta cláusula el otorgamiento al gobierno federal de un veto («the bestowal upon the federal government of a veto») para ser discretamente («unobtrusively») ejercido a través del departamento judicial, sobre ciertas categorías de legislación estatal, interpretación que, no obstante provenir de una autor de la talla del Profesor de la Princeton University, nos parece notablemente desafortunada.

Una dilatada jurisprudencia de la Corte ha delimitado la competencia judicial con singular nitidez ${ }^{35}$, entendiendo a grandes rasgos que el conocimiento de «casos y controversias» ha de ser interpretado como excluyente de la consideración por los tribunales federales de cualquier caso que no cumpla estos cuatro requisitos: $1^{\circ}$ ) el caso debe incluir partes contrarias; $2^{\circ}$ ) las partes deben tener un interés jurídico sustancial; $3^{\circ}$ ) la controversia tiene, por fuerza, que surgir de una serie de hechos reales, y $4^{\circ}$ ) el fallo implica una decisión compulsiva sobre los derechos de las partes ${ }^{36}$.

34 E. S. CORWIN: «The Supreme Court and Unconstitutional Acts of Congress», op. cit., págs. 618-619.

35 Buen ejemplo de ello lo constituye el caso Aetna Life Insurance Co. v. Haworth (1937), en el que el Chief Justice Charles Evans Hughes, hablando por la Corte, aducía que «una controversia jurisdiccional se distingue de una diferencia o disputa de carácter hipotético o abstracto (...). La controversia debe ser determinada y concreta, con referencia a las relaciones jurídicas de las partes que tengan intereses jurídicos opuestos (...). Debe ser una controversia real y sustancial que admita un remedio específico a través de una resolución de carácter definitivo».

36 C. H. PRITCHETT: La Constitución Americana, Tipográfica Editora Argentina, Buenos Aires, 1965, pág. 136. 
II. Más allá de la jurisprudencia tan sumariamente mencionada, a los efectos de este trabajo y del ámbito temporal al que se circunscribe, creemos que tiene un mayor interés mostrar cómo desde los primeros momentos la Supreme Court fue plenamente consciente de su competencia constitucional, rechazando bien pronto el conocimiento de las llamadas advisory opinions. Como recuerda Schwartz ${ }^{37}$, el Justice Louis D. Brandeis solía decir que lo que la Corte Suprema no hizo fue a menudo más importante que lo que hizo. El hecho de que el más alto tribunal actúe como un law court ha sido más importante que cualquier otro factor en la determinación de las cosas que la Corte no hace en el sistema constitucional americano.

En julio de 1793, la Supreme Court iba a tener la oportunidad de pronunciarse al respecto. El Secretario de Estado, Thomas Jefferson, en nombre del Presidente Washington, escribía a los Justices solicitando su asesoramiento (advice) sobre un cierto número de cuestiones legales de Derecho internacional suscitadas de resultas de la ruptura de hostilidades entre Francia e Inglaterra y en conexión con la Neutrality Proclamation de 1793. Jefferson prologó las específicas peticiones con la cuestión general de si el poder público podía con propiedad valerse de tal asesoramiento («wether the public may, with propriety, be availed of — the Justices— advice on these questions» $)^{38}$. El Chief Justice Jay y sus Asociados pospusieron primero su respuesta hasta que la Corte como tal pudiera pronunciarse y entonces, tres semanas más tarde, la Corte se pronunció. La respuesta a la cuestión previa fue negativa, rehusando la Corte dar al Presidente el asesoramiento requerido $^{39}$. El rechazo al desempeño de funciones no judiciales iba a reflejar, a juicio de McCloskey ${ }^{40}$, una perspicaz idea, la de que la posición de la Corte dependía, en último término, de la preservación de su diferencia frente a los otros poderes ( «on preserving its difference from the other branches of government»).

Con su rechazo a dar la opinión consultiva reclamada por Washington, la Corte Suprema no sólo adoptaba una contundente interpretación del Art. III, sino que, a la par, como dice Warren ${ }^{41}$, sentaba un precedente de inmensa importancia para el sistema gubernamental, del que, por lo demás, nunca se ha apartado. Para valorar más adecuadamente el carácter innovador de tal decisión, quizá convenga recordar que la Constitución de Massachusetts de 1780 había establecido que «the highest court» del Estado podía ser instada para que diera su opinión (una advisory opinion obviamente) acerca de la validez de una propuesta de acción legislativa, una iniciativa legislativa en definitiva, lo que, como

37 B. SCHWARTZ: A History of the Supreme Court, Oxford University Press, New York/Oxford, 1993, pág. 24.

38 D. P. CURRIE: «The Constitution in the Supreme Court. 1789-1801», en The University of Chicago Law Review (U. Chi. L. Rev.), Volume 48, 1981, págs.819 y ss.; en concreto, pág. 828.

39 «We have considered — razonan los Jueces — the previous question... (regarding) the lines of separation drawn by the Constitution between the three departments of the government. These being in certain respects checks upon each other, and our being judges of a court in the last resort, are considerations which afford strong arguments against the propriety of our extrajudicially deciding the questions alluded to, especially as the power given by the Constitution to the President, of calling on the heads of departments for opinions, seems to have been purposely as well as expressly united to the executive departments». Apud David P. CURRIE: «The Constitution in the Supreme Court», op. cit., pág. 829.

40 R. G. McCLOSKEY: The American Supreme Court, op. cit., pág. 20.

41 C. WARREN: «The First Decade of the Supreme Court of the United States», en The University of Chicago Law Review (U. Chi. L. Rev.), Volume 7, 1939-1940, págs.631 y ss.; en concreto, pág. 646. 
se ha señalado ${ }^{42}$, encontraba su precedente en la historia inglesa, aunque la experiencia inglesa tuviera un ámbito limitado, no obstante lo cual ese precedente impregnó los orígenes de la historia constitucional norteamericana, por lo menos a nivel estatal ${ }^{43}$. Ciertamente, como ya hemos expuesto, y es bien conocido, el Art. III se refiere a la competencia de la Corte para conocer de «casos y controversias», pero también es cierto que al no prohibir explícitamente el conocimiento de otro tipo de asuntos, no cabía descartar que la Supreme Court se hubiera pronunciado de un modo diferente. No lo hizo para salvaguardar de modo más adecuado su independencia.

Siendo la que acabamos de mencionar la primera ocasión en que la Corte como tal tuvo oportunidad de manifestar su rechazo acerca de las advisory opinions, lo cierto es que un año antes, en 1792, en el Hayburn's Case, los Justices se enfrentaron con una coyuntura propicia para establecer un importante precedente en relación a la justiciabilidad de ciertos asuntos y a la judicial review, que de algún modo viene a complementar lo anteriormente expuesto. En marzo de 1792 el Congreso aprobaba una ley que disponía que los United States Circuit Courts (tres en total en todo el país, de conformidad con la Judiciary Act, que desde 1789 hasta 1793 se integraron por dos Associate Justices de la Corte Suprema y por un Juez de Distrito) habían de conocer de aquellas demandas de los veteranos de la Guerra de Independencia reclamando una pensión de incapacidad, tras lo que los mencionados tribunales habían de emitir un certificado de su decisión, enviándolo al Secretario de Guerra, que podía a su vez conceder o denegar la pensión, según considerara pertinente. Cinco de los seis Justices por aquel entonces integrantes de la Corte Suprema (el Chief Justice Jay y sus Asociados Cushing, Wilson, Blair y James Iredell), ejerciendo sus funciones de Jueces de los tres Circuit Courts ${ }^{44}$, presentaron opinions bajo la curiosa forma de cartas dirigidas al Presidente Washington, declinando actuar en las condiciones explicitadas por la mencionada ley. Todos los Jueces coincidieron en que la ley imponía «nonjudicial duties on the courts», violando de esta forma el principio de separación de poderes. Asimismo, los cinco estuvieron de acuerdo en el rechazo del «implied power» que la ley atribuía al Secretario de Guerra, un miembro del ejecutivo, de revisar o rehusar el cumplimiento de lo decidido por el Circuit Court.

Particular interés presentan algunas de las reflexiones vertidas por el Chief Justice Jay y por el Justice Cushing, actuando como miembros de tribunales de circuito. John Jay, en el ejercicio de sus funciones en el first Circuit Court (New York), ya había tenido oportunidad de efectuar unas reflexiones de la mayor relevancia en lo que ahora importa. En efecto, el 4 de abril de 1790, esto es, dos años antes del Hayburn's case, argumentaba que era «of the last importance to a free people that they who are vested with Executive, Legislative and Judicial power should rest satisfied with their respective portions of power

42 O. P. FIELD: «The Advisory Opinion-An Analysis», en Indiana Law Journal (Ind. L. J.), Vol. 24, 1948-1949, págs. 203 y ss.; en concreto, pág. 203.

43 «From the beginning of our constitutional history — escribe Field — some agency has been exercising the power to tell legislative bodies that they were or were not acting within their power. For a time it was an external agency, the Privy Council. Later the state and national courts took over the task». O. P. FIELD: «The Advisory Opinion-An Analysis», op. cit., pág. 203.

44 El Chief Justice John Jay y el Associate Justice William Cushing en el Circuit Court for the district of New York; los Justices James Wilson y John Blair, en el Circuit Court for Pennsylvania, y el Justice James Iredell, en el Circuit Court of the North Carolina. 
and neither encroach on the provinces of each other, nor suffer themselves nor the others to intermeddle with the rights reserved by the Constitution of the people» ${ }^{45}$. Justamente dos años más tarde, en el caso que nos ocupa, Jay y Cushing, actuando como miembros del first Circuit Court, consideraban que el gobierno se halla dividido en tres «distinct and independent branches» y que es deber de cada una de ellas «to abstain from and to oppose encroachments on either», para añadir de inmediato que «neither the Legislative nor the Executive branch can constitutionally assign to the Judicial any duties but such as are properly judicial and to be performed in a judicial manner», punto de vista plenamente compartido por los Justices Wilson, Blair y James Iredell en otros casos sobre los que tuvieron que pronunciarse en los Circuit Courts.

El caso iba, sin embargo, a llegar en agosto de 1792 a la Supreme Court ${ }^{46}$, al ser ésta requerida para que dictara un mandamus al Circuit Court of Pennsylvania a fin de obligarle a actuar de acuerdo con la antes mencionada ley, esto es, a que procediera y escuchara la petición del Sr. Hayburn de ser colocado en la lista de los pensionistas inválidos. El Attorney General Sr. Randolph formuló una muy elaborada descripción de los poderes y deberes de la Corte, aconsejando la ejecución de la cuestionada norma legal. La Corte se manifestó en el sentido de que tomaba la moción bajo consulta hasta el siguiente período de sesiones («the motion under advisement, until the next term»), aunque la realidad sería que ninguna decisión llegó a pronunciar en torno a esta cuestión. Se ha dicho ${ }^{47}$ que ninguna duda existía acerca de la improcedencia de la ley habríamos de entender que por su obvia inconstitucionalidad- pero que el deseo de evitar un conflicto con los otros poderes era tan grande, que ello condujo a la Corte a su posición, diríamos que un tanto salomónica, de postergar temporalmente la decisión, que a la postre se traduciría en la no resolución del caso. El Hayburn's Case vino a sentar un precedente de sustancial importancia, por cuanto a partir del mismo se entendió que los jueces federales no podían actuar en aquellos casos en que sus decisiones estuvieran sujetas a revisión por el ejecutivo o el legislativo ${ }^{48}$. Adicionalmente, el caso en cuestión ha sido considerado desde tiempo atrás como un paso significativo en el camino conducente al reconocimiento de la facultad del poder judicial de inaplicar las leyes que considerase inconstitucionales. Como señalara hace un siglo Corwin ${ }^{49}$, en los años siguientes al Hayburn case, la Corte Suprema pareció estar completamente de acuerdo («pretty well agreed») en cuanto a su deber de rehusar la aplicación de una ley inconstitucional del Congreso («its duty to refuse enforcement to an unconstitutional act of Congress») y asimismo en cuanto a su facultad de declarar tal ley nula («its power to pronounce such an act void»).

45 Apud C. WARREN: «The First Decade of the Supreme Court of the United Stares», op. cit., págs. 645646.

46 Los aspectos fundamentales del Hayburn's Case pueden verse en The Founders 'Constitution, edited by P. B. KURLAND and R. LERNER, op. cit., volume four, págs. 255-257.

47 C. B. ELLIOT: «The Legislatures and the Courts: The Power to Declare Statutes Unconstitutional», en Political Science Quarterly, Vol. 5, No. 2, June 1890, págs. 224 y ss.; en concreto, pág. 243.

48 B. SCHWARTZ: A History of the Supreme Court, op. cit., pág. 26.

49 E. S. CORWIN: «The Establishment of Judicial Review (II)», en Michigan Law Review (Mich. L. Rev.), Volume IX, 1910-1911, págs. 283 y ss.; en concreto, pág. 285. 
Quedarían inconclusas estas someras reflexiones acerca de la función a ejercer por la Corte Suprema si no añadiéramos algo. La Constitución, ya desde los primeros momentos de la vida de la nueva nación, se convirtió en un símbolo de devoción patriótica. Y la Corte Suprema iba heredar esa calidad simbólica cuasi-religiosa vinculada a la doctrina de la higher law, aunque, desde luego, ello no se hiciese patente en los años que anteceden a Marshall. Pero el dogma de la soberanía popular también continuó sobreviviendo y floreciendo, y, por lo mismo, influenciando el constitucionalismo. La propia Constitución no podía llegar a ser el seguro e inmutable código de la conducta gubernamental que, como dice $\mathrm{McCloskey}{ }^{50}$, algunos de sus idólatras de los últimos días imaginaban que era. Concebida en la ambigüedad al igual que en la libertad, nunca podía escapar a este legado. Y la perdurabilidad de su valor simbólico iba a depender de la flexibilidad de la norma constitucional para dar una adecuada respuesta a las cambiantes necesidades nacionales. Y de resultas de todo ello, la Supreme Court iba a heredar una enorme responsabilidad para ayudar a guiar a la nación en aquellas cuestiones de valor a largo plazo (those long-term «value questions»), debiendo actuar, como de nuevo aduce el profesor de Harvard $^{51}$, tanto como tribunal judicial cuanto como preceptor político, sensible, pero no servil, a las expectativas populares.

\section{B) La Judiciary Act de 1789}

I. El Art. III de la Constitución iba ser desarrollado por la Judiciary Act de 24 de septiembre de 1789, que fue el Senate Bill $\mathrm{n}^{\circ} 1$, en la primera sesión del primer Congreso. Esta ley ha sido vista a menudo como la encarnación de aquel precepto constitucional, suposición que no deja de tener cierta validez si se piensa que muchos de quienes intervinieron en el diseño normativo del texto legal habían participado en la elaboración de la Constitución ${ }^{52}$. Tal sería el caso, por ejemplo, de Oliver Ellsworth, el principal arquitecto de la Judiciary Act, que más tarde llegaría a ser Chief Justice.

Un síntoma de la ansiedad que algunos sentían por contar lo antes posible con un poder judicial federal en funcionamiento, así como, por supuesto, de la trascendencia que se otorgaba de antemano al judiciary, podemos encontrarlo en algunos de los párrafos de la carta que James Sullivan — que muy pronto llegó a ser el Attorney general de Massachusetts - escribía a su amigo Elbridge Gerry, en aquel momento miembro de la Cámara de Representantes, más tarde Gobernador de ese mismo Estado, en la que, tras solicitarle noticias acerca de la formación del judiciary, podía leerse lo que sigue: «The

50 R. G. McCLOSKEY: The American Supreme Court, op. cit., págs. 9-10.

51 Ibidem, pág. 14.

52 Sosin ofrece el dato aproximado de que la mitad de los hombres que habían ayudado a diseñar la Constitución en Filadelfia, fueron miembros dos años después del primer Congreso que se reunió en Nueva York. Así, de los veinte senadores que presentaron sus credenciales en los inicios del primer Congreso o muy poco después, diez de ellos habían ocupado un escaño en la Convención de Filadelfia, incluyendo a los tres que tendrían mayor protagonismo en la elaboración de la Judiciary Act: Oliver Ellsworth, el protagonista principal, William Paterson y William Samuel Johnson. J. M. SOSIN: The Aristocracy of the Long Robe. The Origins of Judicial Review in America, Greenwood Press, New York/Westport (Connecticut)/London, 1989, pág. 275. 
freedom of the people depends so much upon the proper arrangement of this part of the government» 53 .

El 12 de junio de 1789, un Comité nombrado por el Senado para la organización del sistema judicial presentaba un proyecto de ley («a bill») diseñado primigeniamente por Oliver Ellsworth y William Paterson, estableciendo a grandes rasgos una Corte Suprema integrada por seis jueces y una organización de la justicia federal estructurada en los tribunales de circuito y en los de distrito, a los que se otorgaba la competencia de juzgar casos penales y casos relativos a la jurisdicción marítima y del almirantazgo, así como la de conocer de aquellos litigios que tuvieren lugar entre ciudadanos de diferentes Estados. La cuestión crucial a dilucidar por este texto legal, como admite la generalidad de la doctri$\mathrm{na}^{54}$, iba a ser la de decidir si tenía que haber tribunales federales inferiores, quizá con la sola salvedad, no cuestionada, de la jurisdicción marítima y del almirantazgo. Si este tema desencadenó bastante debate, dada la existencia de posiciones maximalistas muy enfrentadas, la composición de la Supreme Court no suscitó por contra divergencias apreciables.

Quince meses después de que la Constitución federal superase la exigencia de la ratificación por nueve Estados, de los trece entonces existentes (como ya se dijo, en junio de 1788) era aprobada la Judiciary Act, considerada con el paso de los años «probably the most important and the most satisfactory Act ever passed by Congress ${ }^{55}$. Las alabanzas sobre este texto legal han sido tantas a lo largo del tiempo, que, como en 1925 señalaban ese gran Juez que sería Frankfurter, bien que cuando todavía no había accedido a la $S u$ preme Court (lo que sucedería en 1939), y Landis, en un trabajo ya en verdad clásico ${ }^{56}$, las mismas han llegado a obscurecer el auténtico significado de la ley. Sin embargo, estos elogiosísimos juicios sobre la ley no nos pueden hacer ignorar que no siempre el texto legal suscitó tan favorables opiniones. Todo lo contrario. Durante su primer medio siglo de vida, desencadenó las más negativas valoraciones ${ }^{57}$.

La realidad es que la Judiciary Act fue un compromiso que de algún modo se vinculó con el destino de varias de las enmiendas formuladas en su momento frente al Art. III de

53 Apud M. MARCUS and N. WEXLER: «The Judiciary Act of 1789: Political Compromise or Constitutional Interpretation?», op. cit., pág. 14.

54 Entre otros varios, C. WARREN: «The First Decade of the Supreme Court...», op. cit., pág. 631.

55 Tal juicio era vertido por el Justice Henry Brown, una vez que había dejado de ser miembro de la Corte Suprema (lo sería entre 1891 y 1906), en un discurso (address) pronunciado ante la American Bar Association el 20 de agosto de 1911. Brown añadiría a su ya más que elogioso juicio, que «the wisdom and forethought with which it was drawn have been the admiration of succeeding generations». De ello se hace eco, en un minuciosísimo trabajo sobre el proceso de génesis de la Judiciary Act, Warren, el historiador por antonomasia de la Corte Suprema. C. WARREN: «New Light on the History of the Federal Judiciary Act of 1789», en Harvard Law Review (Harv. L. Rev.), Volume XXXVII, 1923-1924, págs.49 y ss.; en concreto, pág. 52.

56 F. FRANKFURTER and James M. LANDIS: «The Business of the Supreme Court of the United States - A Study in the Federal Judicial System (I)», en Harvard Law Review (Harv. L. Rev.), Volume XXXVIII, 1924-1925, págs. 1005 y ss.; en concreto, pág. 1008.

57 El senador por Virginia William Grayson, inmediatamente después de su aprobación, tildaba la ley de «monstruous», añadiendo que los Estados se alarmarían con ella y que «its destruction might be predicted». A su vez, en un importante medio periodístico de la época, el Independent Chronicle de Boston, en su edición del 16 de septiembre de 1790 , se hacía referencia al «extensive, perplexing and distressing Judiciary system — a system which, in its operation, will, in time, involve the people of these States into the most ruinous and distressing lawsuits (...) so tedious and intricate a Judiciary system». Cit. por C. WARREN: «New Light on the History of the Federal Judiciary Act of $1789 »$, op. cit., pág. 52, nota 8 . 
la Constitución. Ya hemos tenido oportunidad de aludir a las objeciones desencadenadas por el mencionado precepto, que tenían como común denominador la amplitud de competencias que el artículo otorgaba al «judicial power». Warren recuerda ${ }^{58}$ que dieciséis de las setenta y nueve enmiendas propuestas por las Convenciones de ratificación de la Constitución federal de Massachusetts, New Hampshire, Virginia, New York y North Carolina, versaban sobre el Judiciary Article, esto es, sobre el Art. III. El compromiso en cuestión se dio entre los puntos de vista más extremos de los federalistas, proclives a que el Congreso atribuyera a los tribunales federales la más plena extensión del poder judicial concedido por la Constitución, y los de aquellos que temían que el nuevo gobierno destruyera los derechos de los Estados, partidarios de que todos los juicios se decidieran primeramente en los tribunales estatales y sólo más tarde, mediante apelación, por la Supreme Court 5 .

II. Tres son los aspectos fundamentales reivindicables de este texto legal. En primer término, la ley concibió una organización judicial que, con todas sus imperfecciones, sirvió al país sin cambios sustanciales casi un siglo. En segundo lugar, a través de la supervisión, vía writ of error, de los tribunales estatales otorgada a la Corte Suprema por intermedio de la famosísima Sección 25, la Judiciary Act creó, como dicen Frankfurter y Landis, "one of the most important nationalizing influences in the formative period of the Republic». Last but not least, quizá una de las mayores realizaciones del texto legal fuera el establecimiento en el naciente país de la tradición de un sistema de tribunales federales inferiores, que, en último término, no era sino la respuesta que el legislador norteamericano daba a una serie de problemas y controversias suscitados en la inmediata etapa anterior.

La Judiciary Act, efectivamente, dividió el país en trece distritos y en tres grandes circuitos judiciales, ubicando en cada uno de ellos un Circuit Court, y estableciendo, en lo que sería una de sus disposiciones más discutidas, que tales tribunales se integrarían por dos Justices de la Corte Suprema y por un Juez de distrito. La cuestión («the failure to provide separate judges for the circuit courts») no dejó de ser particularmente controvertida, hasta el extremo de ser considerada ${ }^{60}$ la más debatida, junto a la Sección 13 de la ley (jurisdicción original de la Corte Suprema) y a la célebre Sección 25 (jurisdicción de apelación de la Supreme Court). Para la mentalidad actual, puede resultar inconcebible una previsión como la que se acaba de referir. ¿Cómo podía ser posible que un Associate Justice (o el propio Chief Justice) de la Corte Suprema tuviesen que integrar otros tribunales? Al margen ya de otras consideraciones de mayor enjundia, la que de entrada saltaba a la vista era la dificultad material de compatibilizar el ejercicio de una y otra función judicial. Sin embargo, esa dificultad se relativizaba a la vista de los escasos períodos de tiempo previstos por la ley para que el Tribunal Supremo desempeñara su función: sólo dos períodos anuales, en los meses de febrero y de agosto. Esto es, el Tribunal no era un órgano cuyos miembros estuvieran llamados a ocupar permanentemente su puesto. La praxis judicial no haría sino ahondar en esa idea de un Tribunal Supremo en permanente período vaca-

58 C. WARREN: «New Light on the History of the Federal Judiciary...», op. cit., pág. 55.

59 Ibidem, pág. 131. Análogamente, J. M. SOSIN: The Aristocracy of the Long Robe..., op. cit., pág. 276.

60 J. M. SOSIN: The Aristocracy of the Long Robe..., op. cit., pág. 277. 
cional. Warren ha estudiado con detalle los días reales en que la Supreme Court sesionó primero en Nueva York y más tarde en Filadelfia, hasta su traslado definitivo a Washing$\operatorname{ton}^{61}$. Sus datos no dejan de sorprender: omisión hecha de los primeros días de febrero de 1790 (el día primero de ese mes tuvo la Corte la primera sesión para su organización), la segunda sesión celebrada también en Nueva York se prolongó tan sólo dos días (2 y 3 de agosto de 1790), no habiéndose en la misma de atender ningún asunto judicial. La tercera sesión, celebrada en febrero de 1791 en Filadelfia, no rompió con esta pauta de brevedad $^{62}$. A modo de resumen, en la década que examinamos, los períodos de sesión de la Corte de los meses de febrero, como término medio, fueron inferiores a dos semanas (con la sola salvedad de febrero de 1796, en que la Corte prolongó sus sesiones durante 37 días), mientras que los períodos correspondientes a los meses de agosto aún duraron menos, prolongándose como media dos o tres días (la excepción fue agosto de 1795, en que la Corte prolongó sus sesiones un total de 17 días). Estos datos explican que los Justices pudieran desplazarse con frecuencia muchos centenares (a veces miles) de kilómetros para atender sus tareas como jueces integrantes de los Circuit Courts.

La relativa compatibilidad temporal en el cumplimiento por los Justices de su doble rol no se iba a traducir en que tan anómala fórmula de integración de órganos judiciales fuera pacíficamente aceptada. El paso del tiempo no haría sino confirmar las discrepancias suscitadas por la norma, propiciando dos reformas legales contrapuestas (en 1801 y 1802) de la Judiciary Act. El propio Washington entendió que el Congreso había impuesto una carga excesiva sobre los Justices, carga que desincentivó el acceso a la Corte y que motivó asimismo el cese de algunos Justices, coadyuvando, desde todos los puntos de vista, en la visión que inicialmente se tuvo de la Corte: la de un órgano devaluado. Las disonancias de la fórmula legal no tardarían mucho tiempo en ser constatadas. La Cámara de Representantes ordenó una investigación sobre el funcionamiento del nuevo sistema judicial federal. Edmund Randolph, Attorney General, fue el encargado de realizar el informe, que finalizaba el 27 de diciembre de $1790^{63}$. El más serio problema señalado en la enumeración que en el informe se hacía de los defectos del texto legal concernía justamente a los deberes de los Justices de la Corte Suprema como miembros de los Circuit Courts. Para Randolph, no había duda de que el máximo órgano judicial exigía una plena dedicación («the work of the Supreme Court, if discharged to the full measure of its requirements, demands the entire energy and talent of its judges»). El Presidente Washington transmitió al Congreso el informe, y el resultado de todo ello fue la Ley de 2 de marzo de 1793, que modificó la composición de los tribunales de circuito de un modo harto discutible, al quedar integrados ahora estos tribunales con tan sólo dos miembros, un Justice de la Corte Suprema y un Juez de distrito, lo que, innecesario es decirlo, imposibilitaba el fallo cuando no hubiere acuerdo entre ellos. El advenimiento del nuevo si-

61 Cfr. al respecto, C. WARREN: «The First Decade of the Supreme Court of the United States», op. cit., págs. 635 y ss.

62 La última sesión celebrada en Filadelfia tuvo lugar en agosto de 1800. Ya los otros dos poderes se habían trasladado a Washington. El 23 de enero de 1801 se habilitaba un pequeño lugar (se habla de «a small committee room») en el primer piso del Senado para que, transitoriamente, pudiera sesionar allí la Supreme Court.

63 Sobre este informe, cfr. F. FRANKFURTER and J. M. LANDIS: «The Business of the Supreme Court of the United States...», op. cit., págs. 1018 y ss. 
glo, en el marco de los profundos enfrentamientos políticos entre federalistas y Jeffersonianos republicanos, traería consigo dos nuevas reformas legales antitéticas y casi seguidas, pero de ellas nos ocuparemos más adelante.

III. No obstante habernos referido ya a diversos aspectos de la regulación legal en verdad polémicos y controvertidos, quizá la problemática fundamental suscitada por la Judiciary Act viniera referida más que a la organización del poder judicial federal, a su jurisdicción y, de modo particular, a la jurisdicción de la Supreme Court. Es cierto que algunos pensaron que la Constitución ya confería jurisdicción a la Corte, y que el Congreso no podía alterarla, pero en realidad lo que la Norma suprema hacía en su Art. III era señalar los límites exteriores de tal poder. Habría de ser, pues, la Ley Judicial de 1789 la que precisara los casos de que iba a entender, teniendo una especialísima relevancia la delimitación de su jurisdicción de apelación, respecto de la cual la cláusula segunda de la sección $2^{a}$ del Art. III reenviaba a lo que estableciera el Congreso ( $« \ldots$ the Supreme Court shall have appellate Juridiction, both as to Law and Fact, with such Exceptions, and under such Regulations as the Congress shall made»).

Fueron las secciones 22 y 25 de la ley las que inicialmente contemplaron la jurisdicción de apelación de la Supreme Court, canalizada a través del llamado writ of error. La sección 22 confería jurisdicción a la Corte en casos civiles frente a las sentencias de los tribunales federales inferiores. La sección 25, la realmente controvertida, otorgó a la Corte competencia para conocer de las sentencias de los tribunales superiores de los Estados y, por lo mismo, para revocarlas o confirmarlas, cuando hubieren invalidado una ley federal o un tratado o rechazado demandas en las que se cuestionase la validez de una ley estatal o de cualquier acto adoptado en ejercicio de la autoridad estatal, con fundamento en su contradicción con la Constitución federal, con los tratados o con las leyes federales. En definitiva, la Corte Suprema era revestida de competencia para conocer en apelación de todas aquellas decisiones de los tribunales superiores estatales en las que se hubiera abordado una cuestión federal. Parece bastante evidente que la necesidad de una disposición como la acogida por la sección 25 residía en la propia Constitución y en su cláusula de supremacía. Así lo venía a constatar de modo implícito Charles Evans Hughes, para quien esa sección se hizo expresamente en respuesta a la misma exigencia que condujo a la creación de la propia Corte Suprema ${ }^{64}$. No fue sin embargo pacífica la adopción de tan importante cláusula normativa, cuya constitucionalidad fue puesta en duda por los que de alguna manera seguían apostando por unos Estados soberanos. En 1816, en el importantísimo caso Martin v. Hunter's Lessee, resuelto por unanimidad (con la ausencia del Chief Justice, que no participó en la decisión) y expresando la opinion of the Court el gran Justice Joseph Story, la Corte se pronunciaría de modo inequívoco en favor de la constitucionalidad de tal cláusula.

Cuestión subyacente a la regulación legal fue la de si la ley contemplaba la facultad de revisión judicial. Para un autor tan relevante como Corwin, la cuestión no admitía la más mínima duda: que la Judiciary Act —escribe ${ }^{65}$ — contemplaba, en el pensamiento de su autor, Oliver Ellsworth, el ejercicio de un poder de revisión por los tribunales nacionales de las leyes del Congreso es algo que apenas puede ser puesto en tela de juicio, pero hasta qué punto («how far») otros aceptaron este punto de vista de

64 C. E. HUGHES: La Suprema Corte de los Estados Unidos, op. cit., pág. 49.

65 E. S. CORWIN: «The Establishment of Judicial Review (II)», op. cit., pág. 283. 
la cuestión, es algo imposible de conjeturar, y ello porque así de silenciosas sobre el tema son las actas del debate en el Congreso de la ley. Se ha puesto de relieve asimismo, que al igual que miembros influyentes de la Convención Constituyente pensaron que la judicial review se hallaba implícita en el Art. III, no faltaron tampoco quienes sobreentendieron que tal facultad judicial latía de modo implícito en la Sección 25 de la Judiciary Act, al visualizarse como un instrumento necesario para asegurar la supremacía de ese poder que se halla más allá de los poderes («the supremacy of the power behind the powers»), esto es, del poder constituyente del pueblo ${ }^{66}$. Otros autores, de modo más inequívoco, han entendido que la sección 25 plasma con toda evidencia que los miembros del primer Congreso asumieron que tanto los tribunales estatales como los federales ejercerían «the power to review statutes on the grounds of constitutionality» ${ }^{67}$.

Otros autores han llegado a semejante conclusión, bien que desde postulados distintos. Tal es el caso de Sosin, quien se interroga acerca de si, dado que la mitad de los miembros de ese primer Congreso había participado en la Convención Constitucional, no sería lógico concluir que la sección 25, implícita o explícitamente, reconocía el derecho («the right») de la Supreme Court a revisar y posiblemente declarar nulas las leyes de la legislatura nacional, o simplemente a revisar las decisiones de los tribunales estatales para asegurar la interpretación uniforme y la aplicación de la autoridad nacional y para impedir la usurpación por los Estados de esa autoridad, al igual que para anular aquellas decisiones de los jueces estatales por las que éstos declararan inconstitucionales leyes de la legislatura nacional. ¿Necesitaba el Congreso reconocer una función ya tan arraigada entre los tribunales? «Such an enactment —responde el propio autor ${ }^{68}$ — would be both redundant and presumptuous». El argumento nos parece bastante razonable, y no sólo porque, como en el mismo se da a entender, ya en la Convención Constitucional quedara más o menos admitida la judicial review, sino porque con posterioridad a la Convención de Filadelfia habían tenido lugar diversas tomas de posición sobre la judicial review en las Convenciones estatales encaminadas a la ratificación de la Constitución federal, y en ellas se habían oído relevantes voces a favor de la misma: Wilson en la Convención de Pennsylvania, Marshall en la de Virginia, Ellsworth en la de Connecticut y Hamilton en la importante Convención de Nueva York. Todos ellos, recordaba Corwin ${ }^{69}$, razonaron con todo detalle («at length») en favor del derecho («for the right») de la Corte Suprema para declarar la nulidad de las leyes inconstitucionales del Congreso, lo que era tanto como defender la teoría de la supremacía judicial («the theory of judicial paramountcy»). Sea como fuere, catorce años después, Marshall se encargaría de confirmar lo que, por muchas razones, era algo que había arraigado desde la época colonial en el Derecho americano.

66 G. CASPER: «The Judiciary Act of 1789 and Judicial Independence», op. cit., pág. 294.

67 B. F. WRIGHT: The Growth of American Constitutional Law, University of Chicago Press (first edition by Houghton Mifflin, Boston, 1942), reprinted, Chicago, 1967, págs. 27-28. Cit. por R. L. CLINTON: Marbury v. Madison and Judicial Review, op. cit., pág. 66.

68 J. M. SOSIN: The Aristocracy of the Long Robe. The Origins of Judicial Review in America, op. cit., pág. 277.

69 E. S. CORWIN: «The Supreme Court and Unconstitutional Acts of Congress», op. cit., pág. 620. 


\section{LA PRE-MARSHALL COURT. SU COMPOSICIÓN Y SUS VICISITUDES}

El $1^{\circ}$ de febrero de 1790, la Corte Suprema se reunía por primera vez en sesión pública en el Royal Exchange de Nueva York — ciudad, no lo olvidemos, que fue la primera capital nacional — sesión a la que por cierto sólo acudirían tres de sus miembros. Un año después, en febrero de 1791, tras el traslado de la sede del gobierno a Filadelfia, la Corte pasó a sesionar en esta última ciudad, primero en la State House y más tarde en el nuevo edificio del City Hall, no lejos del Independence Hall.

El Presidente Washington tenía el mayor aprecio por el rol que estaba llamado a cumplir en el nuevo Estado el poder judicial. En las cartas de nombramiento a los seis miembros iniciales de la Supreme Court escribía ${ }^{70}$ : «The Judicial System is the chief Pillar upon which our national Government must rest $\gg^{71}$. Ese pilar necesitaba hombres fuertes, identificados con la filosofía de gobierno de los Federalists. No sería casual el hecho de que siete de las diez personas que Washington nombró para la Corte hubiesen participado en la Convención Constituyente de Filadelfia. Se ha dicho ${ }^{72}$ que Washington no sólo tenía un claro conjunto de criterios para los candidatos a la Corte ( «a clear set of criteria for Court candidacy»), sino que se adheriría a ellos religiosamente («religiously»), pudiéndose incluir en ese conjunto los siguientes: 1) apoyo y defensa de la Constitución; 2) distinguidos servicios en la Revolución; 3) participación activa en la vida política de la nación o de los Estados; 4) experiencia judicial previa en tribunales inferiores; 5) o una «favorable reputation with his fellows» o vínculación personal con el propio Washington, y 6) conveniencia geográfica («geographic suitability»). De todos ellos, es claro que el primer criterio era, de lejos, el más relevante. Warren, más concisamente, recondujo esos criterios a tan sólo dos: la previa experiencia judicial y también la distribución geográfica $^{73}$, y ambos, como regla general, son empíricamente confirmados si no en la totalidad de sus nombramientos, sí en la gran mayoría de ellos.

A partir de estas premisas, el Presidente Washington procedió a nombrar en 1790 al Chief Justice, cargo para el que resultó elegido John Jay, y a cinco Associate Justices: John Rutledge, William Cushing, James Wilson, John Blair y James Iredell. El Chief Justice, procedente de Nueva York, abogado, jurista, diplomático y también líder político, había contribuído junto a Hamilton y Madison en los artículos de los Federalist Papers. Es conocido que la opción inicial de Washington para la presidencia de la Corte no era Jay sino Rutledge, que a la postre alcanzaría la Chief Justiceship cinco años después, bien que de modo más nominal que real. Procedente de Carolina del Sur, Rutledge, antiguo Go-

70 Apud H. J. ABRAHAM: Justices E Presidents. A Political History of Appointments to the Supreme Court, $2^{\text {nd }}$ edition, Oxford University Press, New York/Oxford, 1985, pág. 72.

71 Esa misma idea del judiciary como «pilar del buen gobierno» era reiterada, entre otros escritos de Washington, en una carta dirigida a Edmund Randolph, el primer Attorney General como ya hemos referido. En ella, Washington escribía: «con la convicción de que la administración de justicia es el más firme pilar del buen gobierno («the firmest pillar of good government»), he considerado el primer acuerdo sobre el departamento judicial (se refiere a los nombramientos de los Justices) como esencial a la felicidad de nuestro país y a la estabilidad de nuestro sistema político». Apud Bernard SCHWARTZ: A History of the Supreme Court, op. cit., pág. 16.

72 H. J. ABRAHAM: Justices E Presidents. A Political History of Appointments..., op. cit., págs. 71-72.

73 C. WARREN: «The First Decade of the Supreme Court...», op. cit., pág. 633. 
bernador de ese Estado y juez de su Chancery Court, deseaba inicialmente la presidencia, aspiración que no se vio finalmente convertida en realidad porque Washington necesitaba rendir homenaje al Estado clave («the key state») de Nueva York, cuya ratificación de la Constitución federal había demostrado ser realmente decisiva ${ }^{74}$. William Cushing era el Chief Justice de la Supreme Judicial Court de Massachusetts. James Wilson, de Pennsylvania, era uno de los firmantes de la Declaración de Independencia; fue miembro enormemente influyente de la Convención de Filadelfia y, al margen de todo ello, era uno de los estudiosos del Derecho más sobresalientes de su tiempo, llegando a ser finalmente Profesor de Derecho de la Universidad de Pennsylvania. John Blair, de Virginia, también había sido miembro de la Convención, aunque con un rol mucho menos destacado que el de Wilson. Sus servicios políticos fueron determinantes, aunque no se puede olvidar que Blair, Madison y el propio Washington fueron los tres únicos miembros de la delegación de los llamados Old Dominion que votaron a favor de la Constitución en su totalidad. En fin, James Iredell, el último en ser nombrado (un año más tarde que los demás), y el más joven en serlo, a la edad de 38 años, había sido Attorney General de Carolina del Norte. Aunque no fue miembro de la Convención, desempeñó un papel muy activo en Carolina del Norte para la ratificación por este Estado de la Constitución.

La realidad, sin embargo, demostraría con cierta crudeza que la Corte Suprema era un órgano debilitado y que el acceso a ella no suscitaba especiales entusiasmos, ni mucho menos podía entreverse como la culminación de una carrera jurídica. Por supuesto, nos referimos tan sólo a esta primigenia etapa de la vida de la institución. Paradigma de ello puede ser considerada la actitud de su primer Presidente, John Jay, y las vicisitudes de su cargo.

En noviembre de 1793, el Gobierno inglés promulgó unas Orders in Council dando instrucciones a sus oficiales de la Armada de incautarse de todos los barcos que fuesen o viniesen de las Indias francesas occidentales. Las consecuencias de ello fueron la captura de cientos de barcos norteamericanos y de sus cargamentos. Así las cosas, Washington decidió enviar un embajador extraordinario a Inglaterra con la finalidad de negociar un tratado resolviendo las cuestiones pendientes entre ambos países. Hamilton era el candidato idóneo para esa misión, pero había llegado a ser tan temido y odiado por la oposición Republicana ( «he had become so feared and hated by the Republican opposition»), que él mismo recomendó a Washington que nombrara al Chief Justice para esa delicada tarea ${ }^{75}$. Ello no obstante, el Tratado con Inglaterra, firmado en 1795, pese a ser conocido como «the John Jay's Treaty», fue en gran parte («largely») hecho por Hamilton $^{76}$. Él ya había conducido el Tratado de paz de 1783 entre los dos países hacia su más plena aplicación, logrando con ello una serie de intercambios comerciales entre ambos países, que siempre se valoraron como muy beneficiosos para la economía norteamericana. Jay aceptó el nombramiento como enviado especial a Inglaterra (recordemos

74 H. J. ABRAHAM: Justices E Presidents. A Political History of Appointments..., op. cit., pág. 73.

75 En tal sentido, D. STALOFF: Hamilton, Adams, Jefferson. The Politics of Enlightenment and the American Founding, op. cit., pág. 111.

76 B. MITCHELL: Alexander Hamilton. A Concise Biography, Oxford University Press, New York, 1976, pág. 287. 
que ya había sido embajador en España en 1779), sin renunciar a su cargo de Chief Justice, no obstante ser denunciado tal nombramiento como violatorio del principio de la separación de poderes. Jay se ausentó de la Corte durante los períodos de agosto de 1794 y febrero de 1795. Finalmente, el 29 de junio de 1795, Jay renunciaba al cargo, que en realidad no ocupaba desde febrero del año anterior. La razón última de su dimisión como presidente de la Corte era su deseo de llegar a ser Gobernador del Estado de Nueva York, cargo para el que, hallándose en Inglaterra y sin dejar de ser Chief Justice, fue nominado y para el que finalmente resultó electo ese mismo año de 1795. Tras el cese de Ellsworth como Chief Justice, en 1800, el Presidente Adams ofreció a Jay de nuevo el cargo de presidente de la Supreme Court, oferta que declinó, recordando al Presidente Adams que había dejado la Corte unos años antes completamente convencido de que un sistema judicial tan defectuoso («so defective») nunca podría obtener «the energy, weight, and dignity which are essential to its affording due support to the national government, nor acquire the public confidence and respect which, as the las resort of the justice of the nation, it should possess ${ }^{77}$.

Alexander Hamilton declinó aceptar el cargo de Jay, supuestamente, por hallarse ansioso de reanudar el ejercicio de la abogacía y sus actividades políticas en Nueva York ${ }^{78}$. No sería desde luego el único estadista en declinar un nombramiento para la Corte Suprema. Edmund Pendleton, de Virginia, y Charles Cotesworth Pinckney, de Carolina del Sur, entre otros varios, también declinaron ser nombrados Justices, lo que, unido a los ceses que con frecuencia se produjeron de miembros de la Corte, da una idea del poco atractivo que tal cargo tenía. Ciertamente, la obligación legal de los Justices de integrar los Circuit Courts no dejó de pesar como una losa en esa escasa pasión por el cargo ${ }^{79}$.

El Presidente Washington tuvo serias dificultades para cubrir la Presidencia de la Corte. John Rutledge, como ya se dijo, uno de los primeros integrantes de la Corte, que había dimitido en 1791 para alcanzar el cargo de Chief Justice de la Court of Common Pleas de Carolina del Sur, fue instado por Washington para que se reincorporara a la $\mathrm{Su}$ preme Court, bien que esta vez como su presidente. Aunque la respuesta de Rutledge fue la de mostrar al Presidente su falta de deseo por ocupar el cargo dejado por Jay, es lo cierto que finalmente se avino, y durante el período de sesiones de agosto de 1795 («the August 1795 Term») Rutledge ocupó de hecho la Presidencia de la Corte. Sucedió, sin embargo, lo inesperado: el Senado votó contra la confirmación de Rutledge en el cargo, en gran medida a causa de su virulento ataque contra el Jay Treaty en un discurso pronunciado en Charleston ${ }^{80}$, pero también por los rumores que circulaban por aquel entonces

77 Apud M. J. KLARMAN: «How Great Were the "Great” Marshall Court Decisions?», en Virginia Law Review (Va. L. Rev.), Volume 87, 2001, págs. 1111 y ss.; en concreto, pág. 1154.

78 En tal sentido, B. SCHWARTZ: A History of the Supreme Court, op. cit., pág. 16.

79 Schwartz se refiere, en su documentada historia de la Corte, a una carta de un congresista, escrita tras la renuncia de Jay a la Chief Justiceship, en la que se hace eco de que una de las razones del abandono de Jay fue «the system of making the Judges on the Supreme Court ride the Circuits throughout the Union». Tal circunstancia habría inducido a Jay a abandonar la Corte, al tener que estar siete meses al año viajando con su familia por todo el país. B. SCHWARTZ: A History of the Supreme Court, op. cit., pág. 19.

80 Según la South Carolina State Gazette, en el meeting de Charleston, Routledge se había quejado de que Jay, indirectamente («by implication») había admitido la subordinación americana a Jorge III y había renunciado a los derechos y privilegios de los ciudadanos de los Estados Unidos. Varios periódicos de Filadelfia, New York, Boston y Providence reimprimieron su discurso, pero no antes de que la Philadelphia Gazette, el 20 de ju- 
acerca de su «accellerated and increased... disorder of the mind ${ }^{81}$. Rutledge es considerado como el segundo Chief Justice de la Corte, pues actuó realmente como tal, si bien, en realidad nunca llegó constitucionalmente a cumplir con los requisitos exigidos para el acceso al cargo, que, por lo demás, desempeñó por un período minimalista (su incorporación al Tribunal se produjo el 12 de agosto y el 15 de diciembre el Senado declinó confirmar el nombramiento).

El siguiente nominado por Washington fue el Justice William Cushing, cuya propuesta de nombramiento fue confirmada por el Senado el 27 de enero de 1796, pero de nuevo surgió una circunstancia imprevista. Cushing declinaba el 2 de febrero asumir la presidencia de la Corte, supuestamente por razones de salud, por lo que, de facto, el Juez de Massachusetts no llegó a ejercer el cargo.

Sería finalmente Oliver Ellsworth, de Connecticut, considerado un «inquebrantable federalista» («a staunch Federalist») ${ }^{82}$, que había sido miembro de la Philadelphia Convention, juez de la Corte Suprema de su Estado y senador, y cuyo rol decisivo en la elaboración de la Judiciary Act (Ellsworth fue el «chairman», esto es, el presidente, del Comité del Senado que preparó el texto legal) ya hemos puesto de relieve, el elegido por Washington como Chief Justice, y quien finalmente iba a desempeñar el cargo que tantas vicisitudes había desencadenado. El 4 de marzo de 1796 se producía el nombramiento, el último de los que haría Washington para la Corte Suprema.

La figura de este Chief Justice presenta particular relevancia. El ejercicio de su cargo senatorial ya atestigua tanto su capacidad como su potencial liderazo («his capacity and potential for institutional leadership» ${ }^{83}$, si bien el corto período de ejercicio del cargo, inferior a cinco años, no posibilitó la plena manifestación de tal liderazgo institucional. Dos aspectos resultan, en cualquier caso, significativos en relación al nuevo Chief Justice. El primero de ellos, al que se ha referido un tan cualificado conocedor de la Corte como Beard ${ }^{84}$, es el de que ya con anterioridad a su acceso al Tribunal (recordemos la inequívoca constatación de Corwin en igual sentido, ya mencionada), Ellsworth había considerado que el poder judicial federal, en el cumplimiento de sus funciones normales, podía declarar una ley del Congreso («act of Congress») que se entendiera contraria a la Constitución federal como nula y sin valor («null and void»), con lo que quizá, de haber ejercido su cargo por un período de tiempo más dilatado, le habría correspondido a él la paternidad de la confirmación por la Corte Suprema de la facultad judicial de la judicial review. Otro aspecto de interés tiene que ver con una realidad procesal de la Corte de Ells-

lio de 1795, anunciara la nominación de Rutledge como Chief Justice por el Presidente Washington. Cinco días más tarde, Edmund Randolph confiaba a Washington que se rumoreaba muy seriamente («it is very seriously whispered») en Charleston, desde hacía dos meses, que Rutledge «tenía seriamente perturbada su mente». A su vez, importantes Federalistas en el Senado se sintieron ofendidos por el discurso de Rutledge. Oliver Wolcot y Timothy Pickering, según el propio Attorney General, Randolph, consideraron el discurso del futuro Chief Justice como una "prueba de la imputación de enajenación» («proof of the imputation of insanity»). Apud J. M. SOSIN: The Aristocracy of the Long Robe..., op. cit., págs. 280-281.

81 B. SCHWARTZ: A History of the Supreme Court, op. cit., pág. 28.

82 H. J. ABRAHAM: Justices E Presidents..., op. cit., pág. 77.

83 R. G. SEDDIG: «John Marshall and the origins of Supreme Court leadership», en University of Pittsburg Law Review, Vol. 36, number 4, Summer 1975, págs.785 y ss.; en concreto, pág. 794.

84 C. A. BEARD: «The Supreme Court-Usurper or Grantee?», en Political Science Quarterly, Vol. 27, No. 1, March 1912, págs. 1 y ss.; en concreto, pág. 6. 
worth. Ésta, desde sus inicios, como abordaremos con mayor detalle más adelante, venía pronunciándose a través de las seriatim opinions. Se viene reconociendo por la doctrina ${ }^{85}$ que Ellsworth intentó durante su presidencia promover sentencias breves, como antesala de un objetivo de mayor alcance, en el que se esforzó hacia el final de su cargo, el de conseguir un consenso entre los Jueces al objeto de alcanzar una decisión única de la Corte («a single opinion»), bien a través del Chief Justice, bien por intermedio del senior Justice. No sería ajeno a todo ello que el propio Chief Justice procediera a escribir algunas majority opinions, anticipando de esta forma, en alguna medida, lo que había de acontecer tras la llegada de Marshall a la Corte.

La trayectoria de Ellsworth en la Chief Justiceship recuerda en alguna medida la seguida por Jay, y no nos referimos ya al análogo período de tiempo de ejercicio de sus funciones en la Corte, sino al sorprendente abandono temporal de las mismas para, sin renunciar al cargo, ejercer funciones diplomáticas. El 25 de febrero de 1799, Ellsworth marchaba a Francia en misión diplomática, y sólo después de más de un año y medio, el 30 de septiembre de 1800, renunciaría definitivamente a la Presidencia de la Corte. Es evidente que estas dilatadísimas ausencias por parte de los presidentes, desempeñando funciones diplomáticas en el extranjero, no hacían sino devaluar hasta el extremo la imagen de la Supreme Court. "That the Chief Justiceship is a sinecure — se escribía en el diario Philadelphia Aurora - needs no other evidence, than that in one case the duties were discharged by one person who resided at the same time in England; and by another during a year's residence in France» ${ }^{86}$.

En el período que ahora nos ocupa, que abarca hasta el 4 de febrero de 1801, fecha en la que Marshall se incorporó efectivamente a la Corte, junto a los hasta ahora mencionados, otro cinco Justices integraron la Corte: Thomas Johnson (en 1792), William Paterson (en 1793), Samuel Chase (en 1796), Bushrod Washington (en 1799) y Alfred Moore (en 1800). Los nombramientos de los tres primeros también correspondieron a Washington, mientras que los dos últimos fueron nombrados por el Presidente John Adams. Thomas Johnson, de Maryland, antiguo Gobernador de ese Estado, era miembro de los tribunales federales inferiores en 1791, momento en el que Washington lo propuso. Reacio a aceptar el nombramiento por su aversión a las incomodidades que se anudaban a la participación de los Justices en los tribunales de circuito ${ }^{87}$, Johnson terminó incorporándose a la Corte en 1792 para, en menos de dos años, presentar su renuncia al cargo. Su sustituto sería William Paterson, de New Jersey, que había sido uno de los más importantes líderes de la Convención Constitucional y que desempeñó una trascendente labor de apoyo de la Judiciary Act, muy valorada por Washington. Particularmente polémica sería la figura de Samuel Chase, de Maryland, que accedería a la Corte en enero de 1796 para cubrir la vacante dejada por el Justice Blair unos meses antes. Héroe de la Revolución y signatario de la Declaración de Independencia, Washington pensó en él incluso como Chief Justice tras el rechazo por el Senado de la propuesta de Rutledge en diciembre de 1795, aunque finalmente se decantara por Ellsworth. El sectarismo federalista de Chase generó muchos problemas a la Marshall Court, poniendo gravemente en peligro

85 Así, entre otros, por R. G. SEDDIG: «John Marshall and the origins...», op. cit., pág. 794.

86 Apud B. SCHWARTZ: A History of the Supreme Court, op. cit., págs. 27-28.

87 H. J. ABRAHAM: Justices E Presidents..., op. cit., pág. 75. 
su independencia y, con ella, el propio y fundamentalísimo principio de la independencia del poder judicial, seriamente cuestionado por Jefferson, no sólo como reacción dimanante de su odio hacia John Marshall, sino también como rechazo de la furibunda actitud partidista mantenida por Chase en determinados momentos de su vida judicial. Todo ello desembocó en el proceso de impeachment del Justice Chase, con el que Jefferson, indirectamente, pretendía acabar con la Corte de Marshall. No es este el momento de analizar tal proceso, por lo que no nos detendremos con algo más de detalle en la controvertida figura de Chase, que, tras superar felizmente el proceso del impeachment (en 1805), continuaría en la Corte hasta 1811.

El Presidente Adams, omisión hecha del nombramiento de Marshall como Chief Justice, nombró a otros dos Justices: Washington y Moore. Abraham ha subrayado ${ }^{88}$ cómo los criterios de Adams para estos nombramientos, aún siendo identificables, son considerablemente menos numerosos que los de Washington, destacando que la exigencia preeminente fue la de que los candidatos tuvieren unas sólidas convicciones federalistas, un criterio, en definitiva, ideológico-partidista. En sintonía con el mismo no resulta extraño que el dato profesional contara muy poco para Adams; de hecho, ni Washington ni Marshall tenían experiencia judicial; por contra, el servicio público fue un elemento muy valorado por el Presidente Adams. Y así, Bushrod Washington, sobrino del primer Presidente, que accedería a la Corte en 1799, había sido legislador estatal en Virginia. Por contra, Alfred Moore sí contaba cuando llegó a la Supreme Court (en 1800) con una amplia experiencia judicial en Carolina del Norte, su Estado, en donde había llegado a ser Juez de la Corte Suprema estatal. Washington desempeñaría el cargo durante una treintena de años, convirtiéndose en uno de los más firmes pilares de la Marshall Court, aun cuando en su trayectoria no falten episodios desafortunados, como fue el de su descenso del bench a la arena política para hacer campaña activa a favor de un candidato a un cargo político, ofendiendo con ello el sentido del decoro y oportunidad de una función como la judicial ${ }^{89}$. Bien es verdad, que mucho más intempestiva al respecto fue la actuación de Samuel Chase, y al margen ya de las concretas posiciones de cada Justice, no faltan autores que han considerado que la Corte en cuanto tal descendió con frecuencia al foso de la controversia política en estos primeros años ${ }^{90}$.

En el otoño de 1800, no mucho antes del nombramiento de Marshall como Chief Justice, el Gobierno norteamericano se trasladó a la ciudad de Washington, la nueva capital, que se hallaba aún en las etapas iniciales de su construcción. Pero lo más curioso y, a la par, qué duda cabe, revelador del débil rol que se asignaba a la Corte en las esferas gubernamentales, fue el hecho de que cuando la ciudad fue planeada, el edificio en que la

88 Ibidem, pág. 80.

89 G. L. HASKINS: «Law versus politics in the early years of the Marshall Court», en University of Pennsylvania Law Review (U. Pa. L. Rev.), Vol. 130, 1981-1982, págs. 1 y ss.; en concreto, págs. 3-4.

90 Tal es el caso de Warnecke, quien escribe: «In Eighteenth Century terms, the Court was conceived as a Deus ex machina, an aristocratic institution in a representative political system, which occasionally would descend into the arena of political controversy to maintain the Newtonian balance among the celestial spheres of government and society». S. WARNECKE: «Constitutionalism, Legitimacy and the American Supreme Court», en Jabrbuch des Öffentlichen Rechts der Gegenwart (JÖR), Band 18, 1969, págs.475 y ss.; en concreto, pág. 481. 
Corte debía ubicarse fue pasado por alto, lo que condujo a que, a partir del 2 de febrero de 1801, fecha en que la Corte se encuentra por primera vez en Washington D.C., el supremo órgano judicial se viera obligado a realizar sus sesiones durante un buen período de tiempo en un humilde apartamento.

\section{LA TRADICIÓN DEL COMMON LAW Y EL PRONUNCIAMIENTO A TRAVÉS DE LAS SERIATIM OPINIONS EN LOS PRIMEROS AÑOS DE LA CORTE SUPREMA}

I. Atender a los antecedentes ingleses en la época colonial es inexcusable para la adecuada comprensión de la futura evolución del sistema judicial norteamericano ${ }^{91}$.

El Privy Council inglés era el órgano competente para conocer en última instancia de los recursos presentados contra las decisiones de los tribunales coloniales, circunstancia por la que se ha visto en este órgano un rol equiparable al ejercido tras la Independencia por la Supreme Court. En el ejercicio de su jurisdicción de apelación, el Privy Council había de adoptar sus decisiones por el voto de la mayoría de sus miembros presentes, tras lo que el pronunciamiento se consideraba como una decisión del órgano en su conjunto. Por una Order del Privy Council adoptada en 1627 se impedía hacer públicas las opiniones particulares $^{92}$. A tenor de la misma: "When the business is to be carried according to the most voices, no publication is afterwards to be made by any man, how the particular voices and opinions went». Si se piensa en el hecho de que la sentencia se formulaba en nombre del Rey, se puede comprender que se impidiera toda voz disidente, pues no parecía lógico que el Rey pudiese hablar simultáneamente con dos voces dispares.

En cuanto a la House of Lords, representaba el supremo tribunal de apelación en relación a los casos litigiosos promovidos ante los tribunales ingleses de common law and equity. Tal función judicial no era visualizada como de una naturaleza diferente a la que ejercitaba el órgano en cuestión como cámara parlamentaria. Si se recuerda que en el siglo XVIII no se autorizaba la publicación de los debates parlamentarios, se puede comprender bien que tampoco fuera posible la publicación de las actas atinentes a los procedimientos judiciales, regla que sólo quebró en 1848. En todo caso, y en lo que ahora interesa, los jueces de la Cámara de los Lores, bien tan sólo de forma oral, a través de su propio speech, bien plasmando más tarde su exposición por escrito, expresaban individualmente las razones en que ellos fundamentaban su propio judgment en cada caso. Ello no era nada extraño por cuanto la tradición inglesa se conecta desde sus orígenes con el rito de la expresión oral de cada juez en audiencia pública. Nadelmann lo pondría de relieve con meridiana claridad: «In England (...), judging was traditionally in public, each

91 Acerca de estos precedentes, cfr. el espléndido y ya clásico trabajo de Karl M. ZoBELL: «Division of opinion in the Supreme Court: a history of judicial desintegration», en Cornell Law Quarterly (Cornell L. Q.), Vol. 44, 1958-1959, págs. 186 y ss. En versión italiana y con el título «L'espressione di giudizi separati nella Suprema Corte: storia della scissione della decisione giudiziaria», en la obra Le opinioni dissenzienti, dei giudici costituzionali ed internazionali, a cura di Costantino Mortati, Giuffrè Editore, Milano, 1964, págs.61 y ss.

92 Cfr. al respecto, Alex SIMPSON Jr.: «Dissenting Opinions», en University of Pennsylvania Law Review and American Law Register (U. Pa. L. Rev.), Vol. 71, 1922-1923, págs. 205 y ss. 
judge stating what he thought the judgment should be» ${ }^{93}$. Y Seddig, escueta, pero significativamente, afirma ${ }^{94}$ : «English courts norms decreed that, generally speaking, judges rarely consulted each other or rendered a general opinion».

El propio Thomas Jefferson, en una carta dirigida al Justice William Johnson (primer Juez del Tribunal Supremo nombrado por él mismo, en mayo de 1804, tras acceder a la Presidencia de los Estados Unidos) con fecha de 27 de octubre de 1822, escribía: «You know that from the earliest ages of the English law, from the date of the year-books, at least, to the end of the IId George, the judges of England, in all but self-evident cases, delivered their opinions seriatim, with the reasons and the authorities which governed their decisions. If they sometimes consulted together, and gave a general opinion, it was so rarely as not to excite either alarm or notice» ${ }^{95}$.

Por lo demás, la mayor parte de las apelaciones en relación a decisiones de los tribunales coloniales concluían en una de las Common Law Courts con jurisdicción de apelación, que obviamente adoptaban sus decisiones seriatim, esto es, a través del pronunciamiento individualizado de cada uno de los jueces, de lo que, como antes se dijo, tampoco diferiría la House of Lords $^{96}$.

Conviene no obstante recordar que la llegada al King's Bench de Lord Mansfield, que lo presidiría entre 1756 y 1788, supuso unos ciertos cambios en cuanto que durante su presidencia forjó una tradición en la que se introdujeron las llamadas «caucus opinions on the King's Bench» ${ }^{97}$, procedimiento del que, no sin cierta impropiedad, se afirma que impidió toda concurring o dissenting opinion ${ }^{98}$. El mismo Jefferson, en la carta dirigida al Justice William Johnson a la que ya hemos aludido, se hacía eco de tal procedimiento; en ella puede leerse lo que sigue: «Cuando Lord Mansfield llegó al tribunal, introdujo la costumbre de las caucasing opinions. Los jueces se encontraban en sus cámaras o en otra parte, aislados de la presencia del público («secluded from the presence of the public»), y preparaban lo que iba a pronunciarse como the opinion of the court. Con la jubilación de Lord Mansfield, Lord Kenyon puso fin a tal práctica, y los jueces

93 Kurt H. NADELMANN: «The Judicial Dissent. Publication v. Secrecy», en The American Journal of Comparative Law, Vol. VIII, numbers I-IV, 1959, págs. 415 y ss.; en concreto, pág. 416. En versión italiana y con el título «Il "dissenso" nelle decisioni giudiziarie (pubblicità contro segretezza)», este trabajo fue publicado en la obra Le opinioni dissenzienti dei giudici costituzionali ed internazionali, a cura di Costantino Mortati, Giuffrè Editore, Milano, 1964, págs. 31 y ss. Y en versión alemana, con el título «Das Minderheitsvotum im Kollegialgericht-Bekanntgabe oder Geheimhaltung?», puede verse en Archiv des öffentlichen Rechts (AöR), 86. Band, Heft 1, Juli 1961, págs. 39 y ss.

94 Robert G. SEDDIG: «John Marshall and the origins of Supreme Court leadership», op. cit., pág. 793.

$95 \mathrm{El}$ texto de la carta puede verse en A. J. LEVIN: «Mr. Justice William Johnson, creative dissenter», en Michigan Law Review (Mich. L. Rev.), Vol. 43, 1944-1945, págs. 497 y ss.; en concreto, págs. 513-515.

96 «In the House of Lords — dirán Kornhauser y Sager - the historic tradition, still honored at least formally, is that each judge gives a "speech", offering both a personal ruling on the outcome of the case and reasons to support that ruling». Lewis A. KORNHAUSER and Lawrence G. SAGER: «The One and the Many: Adjudications in Collegial Courts», en California Law Review, Vol. 81, No. 1, January 1993, págs. 1 y ss.; en concreto, pág. 12.

97 Michael MELLO: «Adhering to our views: Justices Brennan and Marshall and the relentless dissent to death as a punishment», en Florida State University Law Review (Fla. St. U. L. Rev.), Vol. 22, 1994-1995, págs. 591 y ss.; en concreto, pág. 612.

98 «During his tenure — se afirma - Mansfield forged a tradition in which concurring or dissenting opinions were extremely rare». Lewis A. KORNHAUSER and Lawrence G. SAGER: «The One and the Many...», op. cit., nota 23, págs. 12-13. 
volvieron a la de las seriatim opinions, y yo creo que la practican de modo habitual hasta hoy» ${ }^{99}$. El dato relativo al cambio auspiciado en el King's Bench por Lord Mansfield es relevante por cuanto la doctrina no ha dejado de poner de relieve la admiración que sintió el Chief Justice Marshall por la fórmula procedimental introducida por el juez inglés ${ }^{100}$, que tendría alguna influencia sobre el trascendente cambio procedimental que introdujo quien ha sido considerado el verdadero «chief architect of constitutional interpretation» ${ }^{101}$.

II. Las primeras sentencias (opinions) de la Corte Suprema fueron formuladas «in the English manner» ${ }^{102}$, o lo que es igual, «delivering seriatim opinions», esto es, formulando cada juez separadamente su opinion sobre el caso enjuiciado. Tan sólo se podía apreciar una diferencia: mientras la costumbre de The King's Bench era seguir en los pronunciamientos un orden de antigüedad, en la Supreme Court ese orden iba a ser justamente el contrario, comenzando los pronunciamientos el último juez nombrado y finalizando los mismos el senior appointee.

Esta práctica difuminó el impacto de las decisiones e hizo de ellas, como dijera McCloskey $^{103}$, lo menos apropiado para que la Corte fuera considerada como un equal partner en el triunvirato federal. La ausencia de una única voz («a single voice») por parte de la Corte no dejó de tener su impacto sobre la apariencia exhibida por la misma hacia el mundo exterior, algo que ya captó el Chief Justice Ellsworth y que percibiría de inmediato Marshall. Bien es verdad que no habría de transcurrir mucho tiempo para que la Corte adoptase sus propias vías procedimentales, lo que no debe extrañar si se atiende al hecho, subrayado por ZoBell ${ }^{104}$, de que los tribunales del siglo XVIII participaban en funciones de gobierno legislativas o ejecutivas (por lo general, en estas últimas). Un poder judicial independiente no existía ni en la teoría ni en la práctica. Por lo mismo, no puede sorprender que al situarse la Supreme Court a la cabeza de la tercera rama de la tricotomía gubernamental formulada por el constituyente norteamericano, y considerarse por el propio Washington como la «piedra angular» («the keystone») del sistema político ${ }^{105}$, bien pronto adoptase procedimientos no coincidentes con los propios de los órganos jurisdiccionales de la época colonial.

Quizá pueda añadirse, que en el primer caso publicado, State of Georgia v. Brailsford (1792), el Tribunal siguió obviamente la práctica de las seriatim, pronunciándose los jueces en orden inverso a su antigüedad. Cada uno de los seis Justices dio su opinión respecto a la petición de Georgia de un requerimiento en un juicio de equidad («a suit in equity») contra dos ciudadanos de otro Estado. La mayoría del Tribunal se pro-

99 Apud A. J. LEVIN: «Mr. Justice William Johnson, creative dissenter», op. cit., págs. 513-514.

100 Así, entre otros, Michael MELLO: «Adhering to our views: Justices Brennan and Marshall», op. cit., pág. 611.

101 George L. HASKINS: «Law versus Politics in the early years of the Marshall Court», en The University of Pennsylvania Law Review (U. Pa. L. Rev.), Vol. 130, No. 1, November 1981, págs. 1 y ss.; en concreto, pág. 2.

102 Laura Krugman RAY: «Justice Brennan and the jurisprudence of dissent», en Temple Law Review (Temp. L. Rev.), Vol. 61, No. 2, Summer 1988, págs. 307 y ss.; en concreto, pág. 308.

103 Robert G. McCLOSKEY: The American Supreme Court, op. cit., pág. 19.

104 Karl M. ZoBELL: «Division of opinion in the Supreme Court...», op. cit., pág. 192.

105 En una carta que dirigía Washington al Chief Justice John Jay, a la que alude Warren, el Presidente escribía que la Corte «must be recognized as the keystone of our politic fabric». Cfr. al efecto, Charles WARREN: «The First Decade of the Supreme Court of the United States», op. cit., págs. 632-633. 
nunció a favor del injunction solicitado, aunque dos de sus miembros se opusieron. Al pronunciarse en contra el junior Justice Thomas Johnson (que había accedido a la Corte ese mismo año de 1792 en sustitución del Justice Rutledge, y que ocuparía su cargo tan sólo durante seis meses, hasta febrero de 1793), primero en intervenir, se ha podido considerar que al Justice Thomas Johnson le corresponde el reconocimiento de haber sido el primero en suscribir un dissent en la Corte Suprema ${ }^{106}$. Bien es verdad que tal afirmación ha de entenderse en un sentido un tanto impropio por cuanto, a nuestro modo de ver, el dissent adquiere su más plena plasticidad frente a las opinions of the Court. Similar a la anterior nos parece la reflexión de Schwartz, para quien esta primera disidencia lo que viene a entrañar es el establecimiento del derecho de los Justices a expresar públicamente su desacuerdo con el resultado alcanzado por la Corte ${ }^{107}$.

\section{LOS PRIMEROS CASOS RELEVANTES DE LA CORTE EN LA ETAPA ANTERIOR A MARSHALL Y LA DOCTRINA EN ELLOS SUBYACENTE DE LA JUDICIAL REVIEW}

I. Durante el período que nos ocupa la Corte iba a decidir relativamente pocos casos. En los tres primeros años de su existencia, prácticamente, no tuvo ningún asunto que tratar. Ello no obstante, hubo al menos tres casos de significativa relevancia en orden a la interpretación de la Norma suprema: los casos Chisholm v. Georgia (1793), Hylton v. United States (1796) y Calder v. Bull (1798), sin que ello suponga olvidar la existencia de otros litigios en los que el Tribunal hubo de enfrentarse con determinadas cuestiones constitucionales, como sucedió, entre otros, con los casos Ware v. Hylton (1796) y Cooper v. Telfair (1800). Ciertamente, el bagaje de estos años en lo que a la creación de un cuerpo doctrinal constitucional atañe queda a años luz de la Corte regida por John Marshall. Como algún autor ha dicho ${ }^{108}$, sobre el cuerpo de doctrina creado por Marshall, John Jay y Oliver Ellsworth, los dos Chief Justices que le precedieron, dado el carácter casi anecdótico de la presidencia de John Rutledge, nunca podrían haber aprobado un examen. En cualquier caso, los instrumentos básicos de la interpretación constitucional empleados antes de 1801 traspasaron el umbral del tiempo, habiendo llegado a nuestros días. Los primeros Justices de la Corte, a la hora de interpretar la Norma suprema, atendieron al texto de las disposiciones constitucionales determinantes, a las deducciones («inferences») que podían ser extraídas de otras normas constitucionales, a las costumbres contemporáneas («contemporary usages»), a las intenciones y propósitos de los Framers y a sus propias concepciones acerca de la política bien fundada («sound policy») ${ }^{109}$. En definitiva, la etapa analizada no es un período de jueces gigantes o de grandes decisiones, pero ello no es óbice para que en estos años la Corte creara un modelo de «constitutional adjudication», esto es, de construcción de una decisión judicial en materia constitucional, que el paso del tiempo no iba a eclipsar.

106 Charles AIKIN: «The United States Supreme Court: The Judicial Dissent», en Jabrbuch des Öffentlichen Rechts (JÖR), Band 18, 1969, págs.467 y ss.; en concreto, pág. 468.

107 Bernard SCHWARTZ: A History of the Supreme Court, op. cit., pág. 20.

108 Walton H. HAMILTON: «The Constitution - Apropos of Crosskey», op. cit., pág. 80.

109 David P. CURRIE: «The Constitution in the Supreme Court. 1789-1801», en The University of Chicago Law Review (U. Chi. L. Rev.), Volume 48, 1981, págs. 819 y ss.; en concreto, págs. 882 y 885. 
II. Chisholm v. Georgia es el primer gran caso que hubo de abordar la Corte en materia constitucional. Decidido el 18 de febrero de 1793, a través de un pronunciamiento seriatim opinions, con el apoyo del Chief Justice Jay y de los Justices Cushing, Wilson y Blair, y con el Justice Iredell en dissent, el caso presenta un conflicto entre la jurisdicción federal y la soberanía estatal, que no podía ser resuelto sin precisar, con carácter previo, qué significado había de darse al término «sovereign» aplicado a los Estados.

El supuesto de hecho no era nada complejo. El Sr. Chisholm, ciudadano de Carolina del Sur y administrador de un acreedor británico que pretendía recobrar el dinero que el Estado de Georgia, receptor de unas mercancías suministradas por el británico, no le había pagado, demandaba a este Estado con vistas a que se hiciese efectivo el pago. La cuestión verdaderamente crucial era la de si un Estado podía ser demandado ante un tribunal federal por un ciudadano de otro Estado.

Las opinions de la mayoría iban a presentar, en términos de Currie ${ }^{110}$, contrastes estilísticos de interés. Blair y Cushing fueron breves y se ciñeron al tema controvertido, circunscribiéndose principalmente a las palabras del texto constitucional. Jay y Wilson formularon opinions más extensas y pretenciosas en las que el lenguaje constitucional desempeñó un rol mucho menor.

La Jay's opinion abordaba a lo largo de tres secciones las tres cuestiones siguientes: 1) en qué sentido había de considerarse Georgia un Estado soberano; 2) si la posibilidad de que el Estado fuere demandado ante un tribunal federal y por un ciudadano ajeno al propio Estado era compatible con su soberanía, y 3) si la Constitución federal autorizaba tal acción frente al Estado. Jay concluirá poniendo de relieve que «la extensión del poder judicial de los Estados Unidos (a las demandas contra un Estado por ciudadanos de otro) me parece acertada («appears to me to be wise») porque es razonable («honest) y útil («useful»)».

Es creencia generalmente admitida ${ }^{111}$ que la opinion más sólida fue la del Justice Wilson. También éste dividió en tres secciones su pronunciamiento, abordando en cada una de ellas la cuestión de la viabilidad de la demanda contra el Estado («the question of suability») desde cada una de estas tres perspectivas: $1^{\text {a }}$ ) desde la óptica de los principios generales de la jurisprudencia; $2^{\mathrm{a}}$ ) desde el punto de vista comparado, esto es, desde las previsiones legales y la práctica de otros Estados, y $3^{\mathrm{a}}$ ) desde la perspectiva de la Constitución de 1787. Wilson consideró que si una libertad individual puede ser sometida a los tribunales, lo mismo debe sostenerse respecto del Estado. Los Estados están sujetos a las mismas reglas de moralidad de los individuos. Pero lo más significativo del parecer de Wilson es su radical repudio del concepto de soberanía estatal: «as the purposes of the Union, therefore, Georgia is not a sovereign state». Como es evidente, el reconocimiento de la soberanía estatal hubiera impedido la admisión de la demanda. Sólo al pueblo de los Estados Unidos, que elaboró la Constitución, era de aplicación el concepto de soberanía.

En definitiva, los jueces de la mayoría entendieron que el Art. III extiende el poder judicial federal a las controversias entre un Estado y los ciudadanos de otro Estado y que la previsión constitucional de que la jurisdicción de la Supreme Court será original en aque-

110 Ibidem, pág. 832.

111 Entre otros, por Bernard SCHWARTZ: A History of the Supreme Court, op. cit., págs. 20-21. 
llos casos «in which a State shall be party» confirma que es indiferente si el Estado es demandante o demandado, pues el término «party» abarca ambas situaciones.

James Iredell se pronunció en dissent. Nacido en Inglaterra, este Justice consideró innecesario decidir si el Art. III viabilizaba o no procesos contra Estados como el controvertido. Su enfoque para decidir el caso fue otro ${ }^{112}$. A su juicio, la jurisdicción original de la Corte Suprema no era «self-executing», o lo que es igual, requería para su concreción de la mediación del legislador. La legislación era incluso necesaria —aducía ejemplificativamente Iredell — hasta para determinar el número de sus jueces. La Sección 14 de la Judiciary Act, seguía razonando el dissenting Justice, autorizaba a la Corte para pronunciarse tan sólo sobre aquellos writs «agreeable to the principles and usages of law», y los principios legales tradicionales, que Iredell derivaba en gran parte de una amplia y erudita investigación del Derecho inglés, no permitían que los gobiernos fueran demandados.

Con todo, el mayor interés de la Iredell's opinion ${ }^{113}$ reside en un dictum que anticipaba en diez años la decisión Marbury v. Madison $(1803)^{114}$, al declarar que la organización y el procedimiento judiciales debían ser establecidos por el Congreso, aun cuando con una limitación, que es: " "that they shall not exceed their authority". If they do, I have no hesitation to say, that any act to that effect would be utterly void, because it would be inconsistent with the constitution, which is a fundamental law, paramount to all others, which we are not only bound to consult, but sworn to observe; and therefore, where there is an interference, being superior in obligation to the other, we must unquestionably obey that in preference. Subject to this restriction, the whole business of organizing the courts, and directing the methods of their proceeding, where necessary, I conceive to be in the discretion of congress». La reflexión es irreprochable y contiene todos los elementos básicos en los que se fundamenta la judicial review: la consideración de la Constitución como norma fundamental y, en coherencia con ello, su primacía sobre todas las restantes, al ser suprema («paramount») a ellas, y la obligación que de ello dimana de observarla y darle preferencia, considerando «completamente nula» («utterly void») toda ley que contrariara la Constitución.

III. La posición de James Iredell estaba lejos de ser nueva. Siete años antes del Chisholm case, Iredell, revelando una mente clara y luminosa, se había manifestado públicamente en favor de la primacía de la Constitución, del carácter limitado del poder legislativo, en cuanto necesariamente sujeto a la Constitución, y de la judicial review. Vale la pena detenernos con un cierto detalle en su espléndida construcción doctrinal. En 1786, Iredell publicaba en un periódico de Carolina del Norte un artículo, «To the Public», en defensa de la autoridad de los jueces para rehusar ejecutar una ley inconstitucional ${ }^{115}$. Iredell comenzaba su artículo poniendo de relieve el radical cambio que suponía la elabo-

112 Cfr. al respecto David P. CURRIE: «The Constitution in the Supreme Court. 1789-1801», op. cit., págs. 835-837.

113 La opinion de James Iredell puede verse en su integridad en The Founders' Constitution, edited by Philip B. KULAND and Ralph LERNER, op. cit., volume five, págs. 408-416.

114 En sentido análogo se pronuncia David P. CURRIE, en Ibidem, pág. 839.

115 James IREDELL: «To the Public», en Correspondence of Iredell, edited by McRee, vol. 2, págs. 145-149. Cit. por Sylvia SNOWISS: Judicial Review and the Law of the Constitution, Yale University Press, New Haven and London, 1990, pág. 45, nota 3. Esta autora se ocupa con gran detalle de la posición de Iredell (pp. 45-53) y de su obra extraemos el texto de Iredell que transcribimos. 
ración de una Constitución, en contraposición al sistema inglés asentado en un poder absoluto del Parlamento: «In forming the constitution (...) —escribía- (we) were not ignorant of the theory of the necessity of the legislature being absolute in all cases, because it was the great ground of the British prentensions (...). When we were at liberty to form a government as we thought best (...) we decisively gave our sentiments against it, being willing to run all the risks of a government to be conducted on the principles then laid as the basis of it...».

Iredell contrastaba más adelante el modelo británico con el asumido por el pueblo americano, asentado en una suerte de relación contractual, que recuerda al contrato social rousseauniano, entre el pueblo y su futuro gobierno, separándose de este modo del sistema inglés, en el que toda ley aprobada por el Parlamento, con la unica salvedad de aquélla que se opusiere a los principios de la justicia natural, vinculaba al pueblo, lo que es obvio que no podía caber en una suerte de relación contractual entre el pueblo y su gobierno, por cuanto que éste venía obligado a respetar los principios contractuales, por así denominarlos, en que se asentaba la relación con el pueblo. «Without an express Constitution — sigue escribiendo quien fuera el más joven de los seis primeros Justices de la Corte - the powers of the Legislature would undoubtedly have been absolute (as the Parliament in Great Britain is held to be), and any act passed, not inconsistent with natural justice (for that curb is avowed by the judges even in England), would have been binding on the people. The experience of the evils which the American war fully disclosed, attending an absolute power in a legislative body, suggested the propriety of a real, original contract between the people and their future Government, such, perhaps, as there has been no instance of in the world but in America». Este peculiar contrato entre el pueblo y sus futuros gobernantes quedaba reflejado en la Constitución, que establecía verdaderamente límites vinculantes respecto de todos los poderes. Consecuentemente con ello, la Asamblea no tiene derecho a violar la Constitución, pero aunque ello es así, Iredell se hace eco de que, de facto, a veces la viola, y ante ello el único remedio es o la petición (ejercer el derecho de petición) o la resistencia universal. Iredell considerará el primer remedio como degradante («demeaning») del autogobierno del pueblo, y el segundo, la revolución, demasiado excepcional y extremo como para ser empleado. Y ante ello, Iredell se cuestiona acerca de si el poder judicial no tendría alguna autoridad para interferir en tales supuestos. He aquí su respuesta: «The (judicial) duty (...) I conceive, in all cases, is to decide according to the laws of the State. It will not be denied, I suppose, that the constitution is a law of the State, as well as an act of Assembly, with this difference only, that it is the fundamental law, and unalterable by the legislature, which derives all its power from it. One act of Assembly may repeal another act of Assembly. For this reason, the latter act is to be obeyed, and not the former. An act of Assembly cannot repeal the constitution, or any part of it. For that reason, an act of Assembly, inconsistent with the constitution is void, and cannot be obeyed, without disobeying the superior law to which we were previously and irrevocably bound».

Llegados aquí, Iredell reivindica la autoridad de los jueces para ejercer la judicial review, rechazando que con ello lleven a cabo una usurpación de poder o ejerzan un poder arbitrario: «The judges — concluye Iredell — therefore, must take care at their peril, that every act of Assembly they presume to enforce is warranted by the constitution, since if it is not, they act without lawful authority. This is not a usurped or a 
discretionary power, but one inevitably resulting from the constitution of their office, they being judges for the benefit of the whole people, not mere servants of the Assembly». Como puede apreciarse en esta magistral construcción, el juez está primariamente sujeto a la Constitución, y no sólo porque ésta es la ley fundamental, sino porque, haciéndolo así, actúa en beneficio del conjunto del pueblo, mientras que dando primacía a una ley que el propio juez considere contraria a la Constitución, lo único que hace es actuar como mero siervo de una Asamblea legislativa que, no obstante hallarse asimismo vinculada por la Constitución, arbitrariamente la ha desconocido.

La construcción de Iredell, a la que él recurriría con frecuencia en los foros, de lo que constituye un buen ejemplo el caso Bayard $v$. Singleton (1787), resuelto por los tribunales de Carolina del Norte, no dejaría a nadie indiferente. Algunas reacciones, como las que seguirían a la resolución del caso inmediatamente antes citado, fueron de gran protesta, al entenderse que tal decisión dejaba al Estado sujeto no a la voluntad de los representes del pueblo, sino de unos cuantos individuos, los jueces en cuestión. Pero la realidad es que en la década de 1790 la construcción de Iredell tendrá un peso específico indiscutible en la consolidación, a nivel doctrinal y judicial, de la inexcusabilidad de la teoría de la judicial review. Y todo ello al margen ya de que esta espléndida construcción dogmática puede considerarse (junto a la de Hamilton) el más sólido antecedente de la doctrina que John Marshall, en nombre de la Supreme Court, consagrará irreversiblemente en 1803.

IV. El Chisholm case causó una tremenda excitación entre los Estados, y de ello derivó la inmediata introducción de resoluciones en el Congreso con vistas a la aprobación de una enmienda constitucional que operara a modo de overruling, derribando la decisión. En cualquier caso, hasta tanto la enmienda en cuestión entró en vigor, se sucedieron las demandas contra los Estados ${ }^{116}$. Finalmente, el 4 de marzo de 1794, tras ser aprobada por la Cámara de Representantes (el 14 de enero lo había sido por el Senado), era aprobada la Enmienda Undécima, cuya ratificación por los Estados quedaría concluida el 7 de febrero de 1795, tras aprobar la Enmienda el duodécimo Estado, Carolina del Norte (en aquel momento la Unión la integraban un total de quince Estados), si bien el anuncio oficial de la ratificación no se produjo sino hasta el 8 de enero de 1798, fecha en que el Presidente Adams, en un mensaje al Congreso, declaró que la Amendment XI había sido adoptada por las $3 / 4$ partes de los Estados y que «may now be deemed to be a part of the Constitution». A tenor de la misma: «The Judicial power of the United States shall not be construed to extend to any suit in law or equity, commenced or prosecuted against one of the United States by Citizens of another State, or by Citizens or Subjects of any Foreign State».

116 A algunas de ellas se refiere Warren, quien recuerda que en junio de 1793, William Vassal, un ciudadano británico cuyas propiedades habían sido confiscadas, presentó una demanda frente a la Commonwealth of Massachusetts, y en 1795, en Oswald v. New York, tras haber dejado el Estado de comparecer y habiendo sido formulada sentencia en rebeldía («judgment by default»), un jurado fue convocado el 5 de febrero, dictando el día siguiente un veredicto de condena por daños contra el Estado por un montante total de 5.415 dólares. Charles WARREN: «The First Decade of the Supreme Court...», op. cit., págs. 642-643. 
La reacción del Congreso para neutralizar con la mayor rapidez el sentido de la Chisholm decision en modo alguno devalúa la sentencia. Más bien todo lo contrario. No han faltado autores que, incluso recientemente, han echado en cara a los Jueces la torpeza de la decisión, en cuanto que la misma contravenía la opinión pública dominan$\mathrm{te}^{117}$, asentando en ello la rápida reacción del Congreso. Nuestra interpretación es diferente. Como hace un siglo escribiera un autor tan riguroso como Corwin ${ }^{118}$, el hecho de la aprobación de la Enmienda XI, lejos de dañar la lógica de la decisión, parece más bien confirmarla («far from impairing the logic of that decision, seems rather to confirm it»). Por lo demás, el tenor de esta decisión no sólo revela, como advierte McCloskey $^{119}$, que la Corte anterior a Marshall fue plenamente consciente de que su gran problema era el relativo a las relaciones entre la Nación (la Unión, si así se prefiere) y los Estados, sino que estuvo profundamente predispuesta ( hheavily disposed») a crear o a alentar la creación de una unión nacional consolidada, y desde esta perspectiva, añadiríamos por nuestra cuenta, la pre-Marshall Court enlaza en su filosofía estrechamente con la Marshall Court. Coherentemente con ello, sería por entero razonable sostener, que si tratamos de visualizar las primeras sentencias de la Supreme Court a cuyo través ésta diseñó los aspectos fundamentales del sistema constitucional de relaciones entre la Unión y los Estados, aunque la pauta general es remontarse al celebérrimo caso McCulloch v. Maryland (decidido el 6 de marzo de 1819 por el voto de los siete miembros de la Corte, expresando la opinion of the Court el Chief Justice Marshall), nos parece evidente que debemos remontarnos más allá en el tiempo, hasta el Chisholm v. Georgia Case. Como escribe Flaherty ${ }^{120}$, quizá la más minuciosa primera consideración («the most thorough early consideration») acerca de la concepción de la soberanía popular mantenida por los autores de la Constitución provino del Chief Justice John Jay en el Chisholm Case. Recordemos algunas de las profundas reflexiones de Jay: «... the people, in their collective and national capacity, established the present Constitution. It is remarkable that in establishing it, the people exercised their own rights, and their own proper sovereignty, and conscious of the plenitude of it, they declared with becoming dignity, "We the people of the United States, do ordain and establish this Constitution". Here we see the people acting as sovereigns of the whole country; and in the language of sovereignty, establishing a Constitution by which it was their will, that the State Governments should be bound, and to which the State Constitutions should be made to conform...».

117 Klarman, refiriéndose a los Justices, escribe: «they handled their first big constitutional decision, Chisbolm v. Georgia, so maladroitly (in the sense of contravening dominant public opinion) that they were immediately slapped down by enormous majorities in both houses of Congress». Michael J. KLARMAN: «How Great Were the "Great” Marshall Court Decisions?», op. cit., pág. 1153. Hemos de precisar por nuestra cuenta que el sesgo de la totalidad del trabajo de este profesor de Historia de la Universidad de Virginia no es precisamente un modelo de equilibrio y objetividad, recordándonos las radicales posiciones antifederalistas de los más exaltados jeffersonianos.

118 Edward S. CORWIN: «The Establishment of Judicial Review (II)», en Michigan Law Review (Mich. L. Rev.), Volume IX, 1910-1911, págs. 283 y ss.; en concreto, pág. 295.

119 Robert G. McCLOSKEY: The American Supreme Court, op. cit., pág. 22.

120 Martin S. FLAHERTY: «John Marshall, McCulloch v. Maryland, and "We the People": Revisions in Need of Revising», en William and Mary Law Review (Wm. E Mary L. Rev.), Volume 43, 2001-2002, págs. 1339 y ss.; págs. $1345-1346$. 
V. Otro litigio de trascendencia constitucional iba a ser el caso Hylton v. United States, decidido el 8 de marzo de 1796 por una votación favorable de los Justices Iredell, Paterson y Chase, que fueron los únicos en pronunciarse, a través del mecanismo de las seriatim opinions ${ }^{121}$.

En 1794, el Congreso estableció un impuesto uniforme geográficamente sobre los carruajes («a carriage tax»), que oscilaba entre uno y diez dólares según el tipo de vehículo. El gobierno norteamericano demandó al Sr. Daniel Hylton ante el tribunal de circuito de Virginia por negarse al pago del impuesto no obstante ser propietario de más de un centenar de carruajes (exactamente, ciento veinticinco, dedicados todos ellos, según manifestaciones del propio Hylton, a su exclusivo uso personal). Hylton esgrimió en defensa de su negativa al pago, que el impuesto era inconstitucional en cuanto que se trataba de un «direct tax» al que le era de aplicación la cláusula cuarta de la Sección $9^{a}$ del Art. I de la Constitución, a cuyo tenor: «No Capitation, or other direct Tax shall be laid, unless in Proportion to the Census of Enumeration herein before directed to be taken», esto es, el Congreso veía prohibido el establecimiento de impuestos directos cuando no se repartieran de acuerdo con la población de los diversos Estados. El asunto llegó en apelación ante la Corte Suprema.

Un dato a subrayar es el de que los métodos de interpretación de los tres Justices que se pronunciaron sobre el caso iban a contrastar claramente con los del Chisholm case, pues mientras en este último caso la interpretación giró en torno al texto de la Constitución, en el Hylton case la interpretación no iba a atender tanto a la literalidad de los preceptos constitucionales $^{122}$. Los tres Jueces, unánimemente, entendieron que el impuesto sobre los carruajes era un impuesto indirecto y, por tanto, no proscrito por el Art. I. Con ello, soslayaron la más espinosa cuestión de la facultad de la Corte de declarar nulas las leyes contrarias a la Constitución. Sin embargo, la Corte no se mostró absolutamente neutra a este respecto. Alguna doctrina lo ha corroborado. Y así, para Douglas ${ }^{123}$, la Corte vino a reconocer la legitimidad de la teoría. También Schwartz coincide en la apreciación, reconociendo que en esta sentencia (al igual que en otras, como las dictadas en los casos Ware v. Hylton y Calder v. Bull) la Corte comenzó a asentar los fundamentos de la judicial re$v_{i e w}{ }^{124}$. No nos cabe la menor duda de que así fue. Para constatarlo, basta tan sólo con leer el último párrafo de la opinion del Justice Chase, que transcribimos a continuación: «As I do not think the tax on carriages is a direct tax, it is unnecessary, at this time, for me to determine, whether this court, constitutionally possesses the power to declare un act of congress void, on the ground of its being made contrary to, and in violation of, the constitution; but if the court have such power, I am free to declare, that I will never exercise it, but in a very clear case». Tan sensata reflexión mueve a entender, de un lado, que para el Justice Samuel Chase la Corte estaba legitimada para llevar a cabo ese control de constitucionalidad y, llegado el caso, declarar nula la ley que se estimare contradictoria

121 Las seriatim opinions de Chase, Paterson e Iredell pueden verse en The Founders' Constitution, edited by Philip B. KURLAND and Ralph LERNER, op. cit., volume three, págs. 357-362.

122 David P. CURRIE: «The Constitution in the Supreme Court. 1789-1801», op. cit., pág. 855.

123 Davison M. DOUGLAS: "The Rhetorical Uses of Marbury v. Madison: The Emergence of a "Great Case” ", en Wake Forest Law Review (Wake Forest L. Rev.), Volume 38, 2003, págs. 375 y ss.; en concreto, pág. 380 .

124 Bernard SCHWARTZ: A History of the Supreme Court, op. cit., pág. 22. 
con la Constitución, y de otro, que ya en aquel temprano momento Chase estaba admitiendo un principio de presunción de constitucionalidad de las leyes, al que anudaba la lógica consecuencia de, que sólo cuando la inconstitucionalidad fuese clara haría efectiva la inaplicación de la ley en contradicción con la Norma suprema.

VI. En estrechísima conexión con el Hylton case ha de situarse el caso Ware v. Hylton, decidido justamente un día antes del anterior, esto es, el 7 de marzo de 1796, por el voto de cuatro Justices (los Jueces Chase, Paterson, Wilson y Cushing) emitidos mediante el procedimiento de las seriatim opinions. Esta decisión, como admite la doctrina generalizadamente ${ }^{125}$, en la dirección de la inmediatamente antes referida, coadyuva a sentar las bases de la judicial review, bien que en este caso ese control recaiga sobre las leyes estatales y venga referido no tanto a la Constitución como a los Tratados internacionales en que fueren parte los Estados Unidos. La Ware decision, en efecto, reconoció la supremacía de los tratados internacionales sobre aquellas leyes estatales en conflicto con ellos. Este caso fue representativo de otros muchos formalizados por acreedores británicos con el objetivo de recobrar las deudas anteriores a la Revolutionary War contraídas por ciudadanos norteamericanos $^{126}$. El Tratado de París de 1783 dispuso que los acreedores no se enfrentarían con impedimentos legales para la recuperación de las cantidades que se les adeudaran. Ello no obstante, el Estado de Virginia aprobó una ley autorizando a sus ciudadanos para pagar las deudas contraídas con súbditos británicos a través de fondos del erario estatal, lo que se traducía en el pago en una moneda depreciada, y a través de ese peculiar pago se les habilitaba para obtener un certificado de pago de la deuda («a certificate of discharge»). El futuro Chief Justice Marshall, actuando en aquel momento como abogado defensor de los intereses del deudor de Virginia, demandado por un súbdito británico ante el tribunal de circuito, argumentó que el Estado tenía «a sovereign right» a confiscar las deudas contraídas con los británicos durante la guerra, que el pago del deudor al que representaba, verificado a través de los fondos del erario estatal, entrañaba un legítimo certificado de pago de la deuda («a lawful discharge of the debt»), y que el Tratado de paz con Inglaterra no podía revivir la deuda sin violar la confianza dada por el Estado y destrozar derechos conferidos. Aunque el tribunal de circuito admitió la argumentación de Marshall, la Supreme Court rechazó tales argumentos ${ }^{127}$.

La Corte Suprema consideró que el Tratado de 1783 había anulado la ley estatal que lo contradecía. Particularmente rotundos serían los argumentos del Justice Samuel Chase. Tras rechazar el argumento de que los poderes de guerra exclusivos no estuvieron en el Congreso, como pronto, hasta 1777, residenciándose hasta entonces en los Estados, tesis que legitimaría la ley estatal, Chase entendería que, en coherencia con ello, Virginia carecía de poder para confiscar las deudas. Los Jueces Cushing y Paterson llegaron a la relevante conclusión de que el Congreso disponía de autoridad en 1783 para rescindir por

125 Entre otros, Bernard SCHWARTZ: A History of the Supreme Court, op. cit., pág. 22. También David P. CURRIE: «The Constitution in the Supreme Court. 1789-1801», op. cit., pág. 863. Para este último autor, «the most important constitutional holding of Ware v. Hylton was that the federal courts had the power to determine the constitutionality of state laws».

126 Apud The Oxford Guide to United States Supreme Court Decisions, edited by Kermit L. HALL, Oxford University Press, New York, 1999, pág. 323.

127 Una exposición detallada de los posicionamientos de los Justices de la Corte en sus seriatim opinions puede verse en David P. CURRIE: «The Constitution in the Supreme Court. 1789-1801», op. cit., págs. 860 y ss. 
medio de un tratado la confiscación establecida por un Estado. Cushing hizo suya tal conclusión, pero Chase fue más allá, ofreciendo argumentos en que sustentarla. A su entender, los Articles of Confederation de 1777 dieron al Congreso «the sole and exclusive right and power of determining on peace or war (...) and of entering into treaties and alliances». Esta concesión no tenía ninguna restricción, por cuanto «el derecho de hacer la paz incluye necesariamente la facultad de determinar en qué términos debe firmarse esa paz. El poder para concluir tratados debe, necesariamente, implicar un poder para decidir los términos en que serán hechos». Y adicionalmente, situándose en la dirección marcada por el Chief Justice John Jay en el Chisholm Case, Chase declaraba: «There can be no limitation on the power of the people of the United States. By their authority, the State Constitutions were made, and by their authority the Constitution of the United States was established». De esta forma, bien puede decirse que Ware v. Hylton puede ubicarse, al igual que Chisholm v. Georgia, entre los antecedentes del McCulloch Case.

La argumentación más trascendente de Chase tendrá en cualquier caso que ver con su interpretación decididamente nacionalista de la cláusula de supremacía del Art. VI de la Constitución, que, a juicio del citado Justice, puede operar retroactivamente para abatir ("prostrate») todas las leyes estales que se opongan a los tratados suscritos por la nación. Es interesante transcribir la reflexión de Chase en sus propios términos: «A treaty cannot be the supreme law of the land (...) if any act of a state legislature can stand in its way (...). Laws of any of the states, contrary to a treaty, shall be disregarded (...). It is the declared duty of the state judges to determine any constitution or laws of any state, contrary to that treaty (...), null and void. National or federal judges are bound by duty and oath to the same conduct». En definitiva, una vez más encontramos en una decisión de esta etapa una decidida defensa de la judicial review, contemplándose ahora como canon del control no ya la Constitución federal, sino los tratados suscritos por la Unión.

VII. Particular trascendencia constitucional iba a tener igualmente el caso Calder v. Bull, decidido el 8 de agosto de 1798, por el voto de cuatro justices: Chase, Paterson, Iredell y Cushing, pronunciándose mediante seriatim opinions, no participando en la decisión el Chief Justice Ellsworth ni el Justice Wilson.

El supuesto desencadenante del litigio vino dado por la promulgación por la Legislatura de Connecticut de una ley (aunque la misma se identificaba como una «resolution») concediendo una nueva vista en un proceso de legalización de un testamento («probate trial»), lo que entrañaba la anulación de la decisión judicial ya dictada, circunstancia que desencadenó que los Calder, herederos legítimos defraudados («heirs at law disappointed»), presentaran la demanda, al considerar la norma como una violación de la prohibición de la Sección $10^{a}$ del Art. I de la Constitución sobre las «ex post facto laws» («No State... pass any... ex post facto Law»), o lo que es igual, de las leyes de efecto retroactivo. Según Corwin ${ }^{128}$, en este caso se enfrentaron los puntos de vista nuevo y viejo de la constitución junto a las distintas percepciones acerca de las bases y el ámbito de la judicial review.

La Corte (muy particularmente la sólida y celebrada opinion del Justice Chase) rechazó la argumentación de la demanda, apoyándose para ello en argumentos muy dispares a los

128 E. S. CORWIN: «The Establishment of Judicial Review (II)», op. cit., pág. 307. 
que Chase acudió para tratar de discernir el significado de la expresión «ex post facto laws», una expresión técnica que venía siendo empleada desde mucho tiempo antes de la Revolución y que había adquirido «an appropriate meaning» entre los legisladores, los abogados y la doctrina; de ahí que tratara de buscar su significado en parte sobre la autoridad de Blackstone, en parte con base en el usus loquendi de las constituciones estatales y parcialmente asimismo con apoyo en la Constitución federal ${ }^{129}$. A juicio de Chase, la prohibición constitucional no se extendía a cualquier legislación retroactiva, sino tan sólo a aquellas leyes que convirtieren lo que eran actos autorizados cuando se realizaron en actos criminales, o que agravaren la pena de actos ya realizados. Chase ${ }^{130}$ calificaría este tipo de leyes o cualquier otra ley similar de «manifestly unjust and oppressive», tras lo que entendería inexcusable distinguir entre «ex post facto laws, and retrospective laws». «Cada ley ex post facto debe necesariamente ser retroactiva, pero no toda ley retroactiva es una ley ex post facto. Sólo las primeras están constitucionalmente prohibidas». En fin, Chase rechazaría que la prohibición constitucional debiera entenderse como un instrumento para asegurar a los ciudadanos en sus derechos personales, por ejemplo, en sus derechos de propiedad $^{131}$. Un sector de la doctrina ${ }^{132}$ ha hecho especial hincapié en las numerosas referencias que la Chase's opinion acoge a principios del Derecho natural, subrayando que no obstante su posición proclive al rechazo de la demanda, su opinion está repleta de sugerencias acerca de «natural rights limitations on legislatures, beyond the limits prescribed by the written Constitution», y en coherencia con ello, Chase rechazará no sólo la omnipotencia de las legislaturas estatales, sino también que su poder sea absoluto y sin control, y ello aun cuando ninguna cláusula específica establezcan al respecto las Constituciones federal o estatal. Con ello, Chase, en línea con precedentes decisiones de la Supreme Court, contribuía a establecer las bases de la judicial review.

La opinion de Chase parecía dejar abierta la vía de un control judicial de las leyes no ya por su contradicción con específicas previsiones constitucionales, sino, más allá de ello, incluso por su contradicción con los principios de la que podríamos llamar «unwritten constitution», por ejemplo, con los principios de la justicia natural. Ello entrañaba dejar planteado un tema dogmático de la mayor trascendencia. Los Justices Paterson ${ }^{133}$ y Cushing concurrieron en la decisión, pero no entraron en el debate dogmático, lo que, por contra, sí iba a hacer el Justice James Iredell, quizá al pensar que Chase estaba sustentando la autoridad para controlar las leyes en sus propias ideas acerca de la justicia, lo que desencadenó una airada reacción de Iredell.

129 E. S. CORWIN: «The Basic Doctrine of American Constitutional Law», en Michigan Law Review (Mich. L. Rev.), Vol. XII, No. 4, February, 1914, págs. 247 y ss.; en concreto, págs. 248-249.

130 Las opinions de Chase, Paterson, Iredell y Cushing pueden verse en The Founders 'Constitution, edited by P. B. KURLAND and R. LERNER, op. cit., volume three, págs. 402 y ss.

131 «The restraint against making any ex post facto laws — razonaba el Justice Chase — was not considered by the framers of the constitution, as extending to prohibit the depriving a citizen even of a vested right to property; or the provision "that private property should not be taken for public use, without just compensation”, was unnecessary».

132 S. SHERRY: "The Founders' Unwritten Constitution», en The University of Chicago Law Review (U. Chi. L. Rev.), Volume 54, 1987, págs. 1127 y ss.; en concreto, págs. 1172-1173.

133 Ello no obstante, en 1795, el Justice Paterson, actuando como miembro de un tribunal de circuito, en el bien conocido caso Van Horne's Lessee v. Dorrance, ya había tenido oportunidad de declarar la inconstitucionalidad de una ley estatal de Pennsylvania, anudando a tal declaración el efecto de nulidad del texto legal. 
Iredell comenzaría señalando que si la constitución no impusiera límites sobre el poder legislativo, la consecuencia de ello sería inevitablemente que "whatever the legislative power chose to enact, would be lawfully enacted, and the judicial power could never interpose to pronounce it void». Admite Iredell que algunos «speculative jurists» (en referencia bastante explícita a Chase) han considerado que una ley del poder legislativo contraria a la justicia natural («against natural justice») debe, en sí misma, ser nula, pero precisa que él no puede pensar que bajo tal gobierno (un gobierno constitucional) ningún tribunal de justicia posea un poder para declararla así (nula), recurriendo en apoyo de su tesis al pensamiento de Blackstone sobre el ámbito del poder parlamentario. Poco después, Iredell esboza con toda nitidez su punto de vista, que por su enorme interés transcribimos con cierto detenimiento:

«If any act of congress, or of the legislature of a state, violates those constitutional provisions, it is unquestionably void; though, I admit, that as the authority to declare it void is of a delicate and awful nature, the court will never resort to that authority, but in a clear and urgente case. If, on the other hand, the legislature of the Union, or the legislature of any member of the Union, shall pass a law, within the general scope of their constitutional power, the court cannot pronounce it to be void, merely because it is, in their judgment, contrary to the principles of natural justice. The ideas of natural justice are regulated by no fixed standard: the ablest and the purest men have differed upon the subject; and all that the court could properly say, in such an event, would be, that the legislature (possessed of an equal right of opinion) had passed an act which, in the opinion of the judges, was inconsistent with the abstract principles of natural justice».

El intercambio dogmático Chase-Iredell ha sido considerado ${ }^{134}$ como la salva de apertura («the opening salvo») de una batalla en marcha («a running battle») que nunca se ha calmado completamente, y en su trasfondo, como un siglo atrás visualizara Corwin $^{135}$, subyace la naturaleza misma de las constituciones.

VIII. Aunque los casos hasta aquí expuestos son los de mayor trascendencia del primer decenio de vida de la Corte, no faltan algunos otros de cierto interés, a los que aludiremos de modo sumario.

Indiscutible relevancia presenta el caso Hollingsworth v. Virginia (1798), respecto del que se ha dicho ${ }^{136}$ que puede ahuyentar («may put to flight») el juicio convencional de que Marbury v. Madison fue el primer caso en que la Corte Suprema consideró inconstitucional una ley del Congreso. La sección 13 de la Judiciary Act, que la Corte había interpretado en el Chisholm case en el sentido de que autorizaba la presentación de demandas por ciudadanos de un Estado contra otros Estados aún estaba en vigor. Al desestimar demandas que entraban dentro de sus previsiones, la Corte interpretó tal disposición como si ya no fuera Derecho, a causa de la Enmienda constitucional sobrevenida, aunque también se admita como posible que lo que en realidad pudo hacer la Corte fue, sin más, llevar a cabo un overruling de su interpretación anterior. Innecesario es decir que el litigio se acomodaba a los supuestos del Chisholm case. No podemos compartir por entero las precedentes interpretaciones, por cuanto no se puede ignorar que la Corte iba a desestimar

134 D. P. CURRIE: «The Constitution in the Supreme Court. 1789-1801», op. cit., pág. 874.

135 E. S. CORWIN: «The Establishment of Judicial Review (II)», op. cit., pág. 308.

136 D. P. CURRIE: «The Constitution in the Supreme Court. 1789-1801», op. cit., pág. 842. 
la demanda el 14 de febrero de 1798, y el 8 de enero de 1798, como ya dijimos en un momento anterior, el Presidente Adams había enviado un mensaje al Congreso comunicando que la Undécima Enmienda había sido ratificada (lo que en realidad había acontecido el 7 de febrero de 1795) y, por lo mismo, podía considerarse parte de la Constitución. Siendo así, no creemos que pueda entenderse que la Corte declarara la inconstitucionalidad de la mencionada cláusula de la Judiciary Act, que tampoco habilitaba de modo específico a los ciudadanos de un Estado para demandar a otro Estado; en todo caso, tendría un soporte más lógico la consideración de que la Corte llevó a cabo un overruling, si bien, en cierto sentido, el overruling lo había formalizado el Congreso al aprobar la Enmienda XI. En realidad, la Corte no hizo otra cosa que aplicar el tenor de tal Enmienda, aunque ello entrañara dejar sin efecto su interpretación anterior.

Por lo demás, en este caso se suscitaron cuestiones de cierto interés. Una de ellas fue la de si la Corte podía obligar a un Estado a comparecer en el proceso, tema delicado que se planteó el 14 de marzo de 1796, cuando el abogado de la parte demandante propuso que la Corte expidiera un writ obligando a la comparecencia del Estado. La Corte pospuso la decisión a consecuencia, según ella misma dijo, de una duda acerca de si el remedio sería proporcionado por la propia Corte o por la Legislatura.

Otro tema relevante abordado por la Corte en el Hollingswort case fue el de los requisitos del Art. V de la Constitución, relativo a la facultad del Congreso de proponer enmiendas a la Constitución. En su decisión, la Corte iba a reconocer que la Constitución no contempla un rol formal a desempeñar por el Presidente en el proceso de enmienda («amendment process»). La Supreme Court rechazó unánimemente el argumento de que la Undécima Enmienda fue adoptada inconstitucionalmente por virtud del hecho de que, tras ser aprobada por el Congreso, la Enmienda no hubiera sido presentada al Presidente para su firma o, en su caso, para la interposición de su veto. Como el Attorney General Lee razonó ante la Corte: «The case of amendments is evidently a substantive act, unconnected with the ordinary business of legislation, and not within the policy, or terms, of investing the President with a qualified negative on the acts and resolutions of Congress» ${ }^{137}$.

Otros casos a los que vale la pena aludir son Van Horne's Lessee v. Dorrance (1795) y Cooper v. Telfair (1800). Vaya por delante que el primero no fue resuelto por la Corte Suprema, sino por el Justice William Paterson, actuando como Juez del United States Circuit Court in Pennsylvania. Su mayor interés se reconduce al nítido posicionamiento expresado por el citado miembro de la Corte Suprema en favor de la nulidad de una ley estatal en contradicción con la Constitución. Warren ${ }^{138}$, hace cerca de un siglo, se hacía eco de cómo los escritores jurídicos, hasta el momento en que él escribía (1922), coincidían en considerar el caso Van Horne como el primer ejemplo («the earliest instance») de una decisión de un tribunal federal, considerando nula una ley estatal por su contradicción con la Constitución. La posición de Paterson venía referida a una ley de Pennsylvania relativa a títulos de tierras contrapuestos en una disputa con Connecticut, pero su argumentación era perfectamente válida tanto para las leyes estatales como para las federales, vi-

137 Apud L. H. TRIBE: American Constitutional Law, volume one, third edition, Foundation Press, New York, 2000, pág. 96.

138 C. WARREN: «Earliest Cases of Judicial Review of State Legislation by Federal Courts», en Yale Law Journal (Yale L. J.), Volume XXXII, 1922-1923, págs. 15 y ss.; en concreto, pág. 15. 
niendo a construir una teoría del poder judicial en su relación con la autoridad legislativa que su colega en la Corte James Wilson había planteado unos años antes en sus clases de Derecho ${ }^{139}$. La posición de Paterson ha sido compendiada en su consideración de que, independientemente de cuál fuera la fórmula de solución del problema en otros países, reflexión que tenía como punto de referencia el ilimitado poder del Parlamento inglés, en el suyo «there can be no doubt that every act of the Legislature repugnant to the Constitution, is absolutely void» ${ }^{140}$.

Es del mayor interés reproducir algunas de las clarísimas reflexiones del Justice Paterson. En su elaborada intervención ante el Jurado, decía: «I take it to be a clear position, that if a legislative act impugns a constitutional principle, the former must give way and be rejected on the score of repugnance. I hold it to be a position equally clear and sound, that in such case, it will be the duty of the court to adhere to the constitution, and to declare the act null and void. The constitution is the basis of legislative authority. It lies at the foundation of all law and is a rule and commission by which both legislators and judges are to proceed. It is an important principle, which in the discussion of questions of the present kind ought never to be lost sight of, that the judiciary in this country is not a subordinate but a co-ordinate branch of the government» ${ }^{141}$.

Muy similar sería la dirección seguida en el caso Cooper v. Telfair (1800), correspondiendo ahora el protagonismo en la Corte Suprema al Justice Samuel Chase, en cuya opinion ofrece un testimonio concluyente («conclusive testimony») de la inminente adopción en el gobierno federal de la «doctrine of judicial paramountcy» ${ }^{142}$. Chase nos viene a decir asimismo que su posición está lejos de ser una postura individual, considerándola, por el contrario, una opinión generalizada en toda la Corte y en algunos de los jueces que actuan en los Circuit Courts. Una vez más, nos parece de la mayor relevancia atender directamente a las propias reflexiones de Chase: «Although it is alleged that all acts of the legislature in direct opposition to the prohibition of the constitution would be void, yet is still remains a question where the power resides to declare it void. It is indeed a general opinion, it is expressly admitted by all this bar, and some of the judges have individually in the circuits decided, that the Supreme Court can declare an act of Congress to be unconstitutional and therefore invalid; but there is no adjudication of the Supreme Court itself upon the point. I concur, however, in the general sentiment...» ${ }^{143}$. No deja de ser peculiar el planteamiento orientado a circunscribir a la Supreme Court la facultad de anular una ley inconstitucional. En cualquier caso, como puede apreciarse a la vista de los diferentes posicionamientos expuestos, el común denominador era bastante claro: la arraigada conciencia de la doctrina de la judicial review entre los miembros de la Corte Suprema y, más allá de ellos, entre otros muchos jueces

139 J. M. SOSIN: The Aristocracy of the Long Robe..., op. cit., pág. 288.

140 Apud H. J. ABRAHAM: The Judicial Process. An Introductory Analysis of the Courts of the United States, England and France, 7th edition, Oxford University Press, New York/Oxford, 1998, pág. 339.

141 Apud C. B. ELLIOT: «The Legislatures and the Courts: The Power to Declare Statutes Unconstitutional», en Political Science Quarterly, Vol. 5, No. 2, June 1890, págs. 224 y ss.; en concreto, pág. 245.

142 E. S. CORWIN: «The Supreme Court and Unconstitutional Acts of Congress», en Michigan Law Review (Mich. L. Rev.), Volume IV, 1905-1906, págs.616 y ss.; en concreto, pág. 628.

143 Apud C. B. ELLIOT: «The Legislatures and the Courts...», op. cit., pág. 245. 
y abogados. La situación estaba lo suficientemente madura como para que Marshall pudiera confirmar, hablando en nombre de la Corte, la que ya en muchos ámbitos judiciales era una doctrina generalmente compartida ${ }^{144}$.

Tiene interés asimismo el caso Wiscart v. D'Auchy (1796), que ha sido considerado ${ }^{145}$ la más importante opinion del Chief Justice Ellsworth, y a través de la cual se formuló una regla básica sobre la propia jurisdicción de la Supreme Court. La cuestión en discusión fue la de si una decisión de equidad («an equity decree») era revisable por la Corte Suprema a través de un writ of error o, por el contrario, de su jurisdicción de apelación. Ellsworth, en un pasaje a menudo repetido, declaró que la jurisdicción de apelación de la Corte dependía por completo de la ley: «If Congress has provided no rule to regulate our proceedings, we cannot exercise an appellate jurisdiction; and if the rule is provided, we cannot depart from it». Esta interpretación sería, sin embargo, rechazada por el Justice Wilson, quien, en una dissenting opinion, alegó que la jurisdicción de apelación de la Corte Suprema derivaba de la Constitución.

Hemos de mencionar finalmente el caso New York v. Connecticut, resuelto el 5 de agosto de 1799, cuyo mayor interés es el de ser la primera decisión que hubo de resolver un litigio entre dos Estados de la Unión. Es curioso constatar que mientras las demandas individuales de ciudadanos de un Estado contra otro Estado suscitaron una violenta indignación y rechazo, tales sentimientos no se produjeron en estos otros supuestos en los que la demanda contra el Estado provenía de otro Estado, aceptándose con normalidad la jurisdicción de la Corte Suprema para la resolución de las «controversies between two or more States», contemplada por la sección segunda del Art. III de la Constitución, quizá, como apunta Warren ${ }^{146}$, porque la experiencia de las colonias y de los propios Estados con anterioridad a 1787 había convencido a todos de la necesidad de que las disputas entre Estados fueran resueltas por la vía judicial, e innecesario es decir que ningún otro órgano jurisdiccional era tan idóneo al respecto como la Supreme Court.

IX. Los casos expuestos con mayor o menor detalle no agotan ni mucho menos el listado de decisiones en que la Corte Suprema se enfrentó con cuestiones constitucionales y asimismo con el problema de la reacción jurídica frente a la dudosa constitucionalidad de una ley. Los casos Chandler v. Secretary of War, resuelto el 14 de febrero de 1794, y United States $v$. Yale Todd, decidido tres días más tarde, constituirían buenos ejemplos de lo que se acaba de decir ${ }^{147}$. Más aún, algún autor ha considerado este último como el primer caso en que la Corte Suprema iba a ejercer la facultad de la judicial re-

144 No deja de ser curioso el caso United States v. Hopkins (1794), en el que se planteó a la Corte una cuestión bastante semejante a la que habría de resolver el caso Marbury v. Madison (1803). El Hopkins case estaba relacionado con una petición para que se expidiera un mandamus por la Corte, con base en su jurisdicción original, contra un Comisario federal de préstamos. Con fecha 15 de febrero de 1794, la Corte decidía que el derecho demandado por el peticionario no parece suficientemente claro para autorizar a la Corte a expedir el mandamus propuesto. Como señalara Warren, la Corte podía muy bien haber decidido como lo hizo Marshall, esto es, que, sin tomar en cuenta el derecho del peticionario al writ of mandamus, la Corte no tenía facultades constitucionales para expedir tal writ a un funcionario federal como un asunto de jurisdicción originaria. C. WARREN: «The First Decade of the Supreme Court of the United States», op. cit., pág. 649.

145 B. SCHWARTZ: A History of the Supreme Court, op. cit., págs. 28-29.

146 C. WARREN: «The First Decade of the Supreme Court...», op. cit., pág. 651.

147 Sobre estos casos, cfr. D. P. CURRIE: «The Constitution in the Supreme Court. 1789-1801», op. cit., págs. $825-828$. 
view ${ }^{148}$ Pero no fue ni mucho menos la Supreme Court el único órgano en enfrentarse al problema de la judicial review, sino que esta facultad de revisión judicial de la constitucionalidad de las leyes también estuvo presente en el ámbito de los tribunales federales inferiores. Ya nos hemos detenido en el Hayburn's case, en el que todos los Justices de la Corte Suprema, actuando como miembros de diversos Circuit Courts, asumieron la facultad judicial de la judicial review, que viene siendo considerado el primer supuesto de ejercicio por los tribunales federales de la función de revisión judicial ${ }^{149}$, y también en el caso Van Horne's Lessee v. Dorrance, con la inequívoca posición a favor de la misma del Justice Paterson, actuando en el tribunal de circuito de Pennsylvania, pero aún se podrían adicionar otros casos.

Tres años antes del último de los casos mencionados, esto es, en 1792, el United States Circuit Court of Rhode Island consideraba una ley de ese Estado nula, de resultas de entender que la misma dañaba las obligaciones dimanantes de los contratos. El propio tribunal se había tenido que enfrentar en distintos casos resueltos en 1791 y 1792 a la cuestión de la validez de las llamadas leyes de moneda de curso legal («legal-tender laws»). Y lo más sorprendente de todo, como dice Warren ${ }^{150}$, es que tan reiterados ejercicios de la judicial review no fueron cuestionados en el propio Estado, cuando en el mismo, tan sólo cinco años antes, se había intentado destituir a los jueces de un tribunal estatal por el solo hecho de considerar inconstitucional una ley del Estado, en un caso bien famoso en la época como fue Trevett $v$. Weeden (1786).

En definitiva, algunos de los grandes temas constitucionales con los que la Corte Suprema comenzó a enfrentarse ya en esta década no quedaron al margen de las decisiones de los tribunales federales inferiores. Ello, por otro lado, respondía a una incuestionable lógica si se piensa en el hecho de que de los Circuit Courts formaban parte jueces del Tribunal Supremo.

\section{$* * *$}

TITLE: The judicial review in the pre-Marchall Court.

ABSTRACT: The frist eleven years of the United States Supreme Court show us a plural mosaic of feelings, perhaps even contradictory each other, with regard to the evaluation of the organ and its decisions. The view of a devaluated Court it is the frist feeling. The Circuit riding's duty of the Supreme Court Justices, the short-lived of its sessions and the reduced number of its opinions are some of the reasons of this devaluation. Nevertheless, if we pay attention to the contents of some decisions, it is possible to change the feelings. Certainly, in this initial stage we don't find noted cases nor impact opinions, but we think that it's indisputable that some decisions contributed to the frist forging of the American constitutional system. With regard to the judicial review of the constituonality of the acts passed by Congress, we shall not be so audacious to question the Marbury v. Madison Myth, but we think that Marbury opinion involves only the formal establishment of a doctrine whose theoretical grounds and historical precedents are present not only in the No. LXXVIII of the "Federalist papers» but also in several decisions of the "pre-Marshcall Court» and in different dogmatic expositions of the first stage's Supreme Court Justices.

148 W. M. MEIGS: «The Relation of the Judiciary to the Constitution», en American Law Review (Am. L. Rev.), Volume 19, 1885, págs. 175 y ss.; en concreto, pág. 186.

149 Entre otros autores, William M. MEIGS, Ibidem, pág. 186.

150 C. WARREN: «Earliest Cases of Judicial Review of State Legislation by Federal Courts», op. cit., págs. 15-16. 
RESUMEN: Los primeros once años del Tribunal Supremo norteamericano nos muestran un plural mosaico de sensaciones, quizá incluso contradictorias, en orden a la calaboración del órgano y sus decisiones. La primera de ellas es la que nos encontramos ante un órgano devaluado. La participación de los Jueces de la Corte Suprema en los Tribunales de Circuito, la corta duración de sus sesiones y el reducido número de sus sentencias, son algunas de las razones de esa devaluación. Sin embargo, si atendemos al contenido de algunas de sus decisiones, las sensaciones pueden llegar a cambiar. Desde luego, en esta etapa inicial del tribunal no nos encontramos con casos célebres ni con decisiones impactantes, pero creemos que es indiscutible, que algunas decisiones contribuyeron a la primera forja del sistema constitucional norteamericno. En relación a la revisión judicial de la constitucionalidad de las leyes aprobadas por el Congreso, no vamos a ser tan atrevidos, como para cuestionar el mito de Marbury v. Madison (1803), pero sí pensamos que la sentencia Marbury entraña tan sólo el establecimineto formal de una doctrina cuyos fundamentos teóricos se hallan presentes no sólo en el $N^{0}$ LXXVIII del «Federalista», sino también en varias decisiones de la Corte anterior a Marshall y en diferentes planteamientos dogmáticos de los Jueces de esta primera etapa del Tribunal.

KeYwords: Alexander Hamilton, John Marshall, Judicial review. Supreme Court Justices. Judiciary Act. 1789. Judiciary. Seriatim opinions. United States Supreme Court.

Palabras Clave: Alexander Hamilton, John Marshall, Judicial review, jueces de la Corte Suprema, Ley Judicial de 1789, poder judicial, Seriatim opinions, Tribunal Supremo norteamericano.

FECHA DE RECEPCIÓN: 02.07.2010. FECHA DE ACEPTACIÓN: 29.07.2011 
